\title{
Innovación editorial en redes sociales de los verificadores hispanos de la \#CoronavirusFactCheck Alliance: contenidos y visión de sus responsables
}

\author{
Editorial innovation on social networks of the \\ \#CoronavirusFactCheck Alliance Hispanic verifiers: contents and \\ vision of those responsible
}

\author{
María Sánchez González. \\ Universidad de Málaga. España. \\ m.sanchezgonzalez@uma.es \\ [CV] 아욜 $\mathbf{A}$ \\ Hada M. Sánchez Gonzales. \\ Universidad de Sevilla. España. \\ misago@us.es \\ [CV] 욜 $\mathrm{A}$ \\ Javier Martos Moreno. \\ Universidad de Sevilla. España. \\ javiermm94@gmail.com
}

Trabajo realizado y financiado en el marco del proyecto de $I+D+i$ "Impacto de la desinformación en el periodismo: contenidos, rutinas profesionales y audiencias (DESINFOPER)". PID2019-

108956RB-I00 (Ministerio de Ciencia e Innovación de España). Septiembre 2020-septiembre 2023

\section{Cómo citar este artículo / Referencia normalizada \\ Sánchez González, M., Sánchez Gonzales, H.M. y Martos Moreno, J. (2022). Innovación editorial en redes sociales de los verificadores hispanos de la \#CoronavirusFactCheck Alliance: contenidos y visión de sus responsables. Revista Latina de Comunicación Social, 80, 135-161. https://www.doi.org/10.4185/RLCS-2022-1535}

\section{RESUMEN.}

Introducción: Este trabajo explora el uso de las redes sociales por medios hispanos de la \#CoronavirusFactCheck Alliance de la International Fact-Checking Network (IFCN) ante la pandemia de la Covid-19 como herramientas para generar contenidos multimedia o interactivos innovadores con los que llegar a nuevos públicos y aumentar su visibilidad. Metodología: Mediante la observación y el análisis de los canales en red se identifican casos relevantes de adaptación de contenidos y se catalogan prácticas innovadoras. Y, a través de entrevistas en profundidad a sus promotores, se determina si esta producción se plantea como estrategia editorial y se recogen percepciones sobre limitaciones, posibilidades y proyectos futuros de contenidos innovadores en red. Resultados: Al margen de la presencia generalizada en Twitter y Facebook, las mayores innovaciones se dan sobre contenidos audiovisuales y sonoros, que van desde resúmenes y curación de contenidos a lo explicativo. Se realizan a través de redes como YouTube, Instagram e incluso TikTok, Twitch y canales de podcasting, empleando narrativas adaptadas a estos canales. Conclusiones: En el marco de determinada estrategia o de forma táctica, más allá de informar, los verificadores buscan formar y movilizar a las audiencias en la lucha contra la infodemia con formatos atractivos, comprensibles y viralizables desde los propios canales donde fluye la desinformación. Si bien algunos cuentan con recursos limitados, participar en la IFCN abre nuevas oportunidades para la innovación editorial. 
PALABRAS CLAVE: verificación; desinformación; redes sociales; contenidos digitales; innovación; cibermedios; Covid-19

\begin{abstract}
Introduction: This work explores the use of social networks by the hispanic platforms of the \#CoronavirusFactCheck Alliance of the International Fact-Checking Network (IFCN) in the Covid-19 pandemic, as tools to generate innovative multimedia or interactive content with which to reach new audiences and expand their visibility. Methodology: By observing and analyzing network channels, we identified relevant cases of adapted digital content and we catalog innovative practices. And through in-depth interviews with its promoters, we determine if this production is considered as an editorial strategy and we collect their perceptions about limitations, possibilities and future projects of online innovative content. Results: Apart from the generalized presence on Twitter and Facebook, the greatest innovations are materialized in videos and podcasts, ranging from summaries and curation of content to explanatory. They are carried out through networks such as YouTube, Instagram and even TikTok, Twitch and podcasting channels, using narratives adapted to these channels. Conclusions: These practices, developed within the framework of a certain strategy or tactically, seek in addition to informing, training and mobilizing audiences in the fight against the infodemic with attractive, understandable and viralizable formats from the same channels where disinformation flows. Although some verifiers have limited resources, joining IFCN opens up new opportunities for editorial innovation
\end{abstract}

KEYWORDS: fact-checking; disinformation; social media; digital content; innovation; cybermedia; Covid-19

\title{
CONTENIDO
}

1. Introducción. 2. Objetivos. 3. Metodología. 4. Resultados. 4.1. Coordenadas y estrategias de difusión básicas en red: canales y audiencias. 4.2. Flujo de información y función de cada red: entre la mera difusión y la generación de contenidos ad hoc. 4.3. Formato, temática y enfoque de contenidos sobre verificación online: catálogo de prácticas. 4.4. Recursos y procesos para la creación de contenidos para redes sociales. 4.5. Casos significativos de innovación estratégica en adaptación de contenidos. 4.6. Distintas fases, misma conciencia. 5. Conclusiones. 6. Bibliografía 7. Currículum Vitae. 8. Anexos

\section{CONTENT}

1. Introduction. 2. Objectives. 3. Methodology. 4. Results. 4.1. Coordinates and basic strategies on the network: channels and audiences. 4.2. Information flow and function of each network: between the diffusion and the generation of content. 4.3. Format, theme and content approach on online verification: catalog of practices. 4.4. Resources and processes for creating content for social networks. 4.5. Significant cases of strategic innovation in content adaptation. 4.6. Different phases, same consciousness. 5. Conclusions. 6. Bibliography 7. Curriculum Vitae. 8. Annexes

\section{Introducción}

La forma actual de consumir contenidos por los usuarios (Martisi, 2020) y difundirlos en redes sociales supone la eliminación del monopolio informativo de medios y periodistas (López, Vives y Badell, 2018). Este contexto de redes y de información cada vez más descentralizada conduce, según Morales (2018), a la desinformación en plena era de la información. Las redes sociales se convierten en fuente de información y, de acuerdo con Masip et al. (2020), en entorno de difusión de bulos por delante de otros canales y medios, porque se apela a las "emociones del miedo o se incita a una acción concreta y al sentimiento de ayuda" (Sánchez, 2020). Esto ha contribuido a la irrupción de verificadores (Spivak, 2011) y a que medios y periodistas velen por la información contrastada para reforzar la confianza de los usuarios en tiempos de post-verdad.

El fenómeno de la fake news, información falsa disfrazada de noticia para obtener un fin político o económico (Amorós, 2018), ha sido extensamente estudiado por la academia en los últimos cuatro años (Blanco et al., 2019), incluyendo estudios realizados en el ámbito iberoamericano (Guallar et al., 2020), más aún ante la Covid-19 y la llamada infodemia global (García-Marín, 2020).

La desinformación ha provocado crisis de confianza en la ciudadanía y, consecuentemente, el llamado fact-checking, práctica centrada en comprobar la veracidad de supuestas informaciones para detectar 
errores y noticias falsas, se ha convertido en la espina dorsal de las actividades periodísticas que han tomado mayor relevancia (Vizoso y Vázquez, 2019). La necesidad de verdad es mayor en el presente siglo porque la "probabilidad de que haya más mentiras es mucho mayor" (Kovach y Rosenstiel, 2003).

Varios estudios abordan este fenómeno y la eclosión de plataformas en España y otros países europeos (Vizoso, López y Pereira, 2019; López Pan y Rodríguez, 2019; Ufarte et al., 2020; García Vivero y López García, 2020), comparan modelos diferenciados de verificadores en cuanto a fórmulas de verificación, organización y contenido (Vázquez Herrero et al., 2019), o evidencian su papel esencial en contextos electorales (Noain-Sánchez, 2019; Magallón-Rosa, 2019) o ante el discurso público en América Latina (Palau-Sampio, 2018).

La International Fact-Checking Network (IFCN), creada por el Instituto Poynter en 2015, tiene como objetivo impulsar principios comunes de verificación asegurando la defensa de hechos no partidistas y transparentes. En su seno surge en 2020 el proyecto colaborativo \#CoronavirusFactCheck Alliance para proporcionar ayuda a los verificadores que la conforman para combatir la desinformación ante la pandemia. Localizamos investigaciones que hacen alusión a esta Red con estudios concretos de plataformas de verificación antes de la Covid-19 (Vázquez-Herrero, Vizoso y López, 2019) y durante ésta (Rodríguez, 2020; Aguado y Bernaola, 2020).

Para las organizaciones de verificación, las redes sociales son un espacio de especial importancia para expandir su labor (Cinelli et al., 2020). Más aún considerando que es en estos canales donde continúa fluyendo gran cantidad de desinformación en la pandemia (Salaverría et al., 2020; Sánchez-Duarte et al., 2020; Pérez-Dasilva et al., 2020; Villa y Cerdán, 2020). Estas redes sociales pueden ser canalizadoras de contenido interactivo y multimedia de rápido consumo (fast content) para captar y fidelizar perfiles más jóvenes, especialmente en plataformas como TikTok y Twitch que, respecto a otras, fomentan la participación fácil e inmediata (Ballesteros, 2020).

Ciertos análisis exploran el uso de uno o varios canales en red por determinados verificadores. La mayoría datan de antes de la conformación de la alianza \#CoronavirusFactCheck, como m-journalism en Maldita (Triviño y Clares, 2019) o WhatsApp por B de Bulo (Palomo y Sedano, 2018). Más recientemente, hallamos estudios de caso sobre ocho verificadores en Twitter (Ramón-Vegas et, 2020), Newtral y Maldito Bulo, en la misma red (Conde-Vázquez et al., 2020), o Newtral en Instagram (González Fernández, 2020).

Se ha identificado también un estudio (Dafonte-Gómez et al., 2019) sobre las redes sociales del conjunto de verificadores hispanos de la IFCN, si bien este data de antes de la pandemia y se limita a realizar un mapa global de su presencia digital, en cuanto a canales y cifras de audiencia. No se han localizado investigaciones que profundicen en sus prácticas de innovación editorial en red desde la doble perspectiva de contenidos y emisores.

Esta investigación explora el uso que estos verificadores realizan de las redes sociales para generar y/o distribuir contenidos digitales adaptados con los que expandir su visibilidad y llegar a nuevos públicos ante la espiral de desinformación generada con la Covid-19. Se determina si esta producción se plantea como estrategia editorial, se elabora una taxonomía de prácticas innovadoras y se analizan los límites, posibilidades y proyectos futuros innovadores en red. Todo ello a partir de la observación y análisis de canales y contenidos, así como desde la visión de sus promotores.

En etapas anteriores del mismo proyecto de $\mathrm{I}+\mathrm{D}+\mathrm{i}$ en el que se realiza el presente estudio, iniciamos el análisis del total de verificadores de la \#CoronavirusFactCheck Alliance, categorizando según un conjunto de rasgos identificativos, organizativos y metodológicos (origen y procedencia, presencia digital, temática, técnica y formatos empleados para verificar, criterios de selección de temas y clasificación de los resultados, etcétera).

Se trata ahora de dar respuesta a preguntas como: ¿Qué función le asignan a cada red social?, ¿qué tipo de contenidos, de qué naturaleza y formatos, sobre verificación se comparten desde estos canales y cuáles de ellos se elaboran ad hoc para los mismos?, ¿cómo y con qué recursos los realizan, disponen de perfiles especializados en ello?, ¿a qué objetivos obedecen, forman parte de determinadas 
estrategias?, ¿cuáles han tenido mayor impacto y cómo valoran desde el medio sus resultados?, ¿con qué limitaciones se encuentran y qué posibilidades y planes de futuro tienen, en cuanto a innovación editorial en red? , ¿̇afecta el tipo de medio a estas prácticas?

\section{Objetivos}

Sobre los verificadores de la \#CoronavirusFactCheck Alliance de la IFCN que vienen desarrollando su labor tanto en España como en diversos países latinoamericanos durante la pandemia planteamos los siguientes objetivos específicos:

OE1. Determinar la presencia de estos verificadores en redes sociales atendiendo a canales disponibles y volumen de audiencias y tipología (propios o compartidos con el medio) en el caso de las secciones de verificación no independientes.

OE2. Identificar tendencias de producción/adaptación de contenidos interactivos o multimedia en red para diferentes canales o distintas audiencias, recopilando casos de referencia y elaborando una clasificación de prácticas innovadoras.

OE3. Conocer, desde la visión de sus promotores, cómo se gestionan las redes sociales (personas y perfiles profesionales, segmentación por canales y públicos, medición de resultados...) y si la generación de contenidos en éstas se plantea como estrategia editorial.

OE4. Recoger su autopercepción acerca de sus resultados en términos de captación/fidelización e interacción con audiencias, extensión de su función social y alfabetización ciudadana a través de estos canales.

OE5. Explorar posibles aspectos limitadores del aprovechamiento de canales en red en la actualidad (debilidades y amenazas) así como oportunidades, innovaciones y proyectos futuros de generación de contenidos en red (visión prospectiva).

\section{Metodología}

El censo de habla hispana está compuesto por cerca de una treintena (29) de proyectos de diversa procedencia geográfica y naturaleza, tanto unidades o secciones de verificación como plataformas independientes, o fundaciones e iniciativas sin ánimo de lucro.

Sobre estos, combinando técnicas cuantitativas y cualitativas de investigación, se ha desarrollado una investigación que, entre septiembre de 2020 y marzo de 2021, ha ocupado varias fases:

1. Categorización de verificadores, observación de presencia digital e identificación de redes sociales (canales y número de usuarios). Partimos de los resultados de la citada investigación propia anterior sobre la totalidad de verificadores de la \#CoronavirusFactCheck Alliance (septiembre a diciembre de 2020). En aquel censo recogimos entre otras variables, a través de una ficha de análisis, la tipología de verificador (medio independiente versus sección o unidad) y su "presencia digital", en cuanto a si disponían de espacio web y canales en red propios o eran compartidos con su medio de origen (mixtos), en el caso de las secciones o unidades de verificación. Las variables que componen esta ficha son: perfiles de redes sociales, tipología de contenidos publicados en redes, formatos, temáticas, metodología de trabajo y estrategias de innovación empleadas. Para este análisis se ha procedido a la supervisión del listado correspondiente a verificadores hispanos, actualizando los datos e incorporando nuevas variables, de las redes sociales propias en Facebook, Twitter, Instagram y YouTube. En el estudio de las redes de los verificadores, el número de seguidores representa un factor importante en el análisis, debido a que permite conocer el alcance de la actividad de estos medios en la audiencia.

2. Realización de entrevistas online en profundidad a responsables de 14 medios, número suficiente para lograr el punto de saturación (Callejo, 1998). Se elaboró una base de datos de responsables de verificadores hispanos, contactando con ellos vía email o redes sociales para entrevistarlos en profundidad por webconferencia. Se escogió esta forma, además de por la pandemia y la dispersión geográfica de los proyectos analizados, por considerar que frente a cuestionarios autoadministrados online, el diálogo síncrono cara a cara daba pie a recabar información complementaria ad hoc. Se lograron realizar, entre diciembre de 2020 y enero de 2021, 14 entrevistas, que cubren a un 50\% aproximado del censo y a casos diversos, tanto secciones de verificación como plataformas independientes, de 
distinta ubicación geográfica (ver tabla 1). Todas fueron grabadas y efectuadas sobre un cuestionario semiestructurado. Se les solicitó información sobre el perfil de sus audiencias, el tipo de informaciones (temáticas, protagonistas, formatos...) que suscitan mayor interés o tienen mayor impacto en redes y casos recientes, el desarrollo o no de contenidos adaptados a distintos perfiles de audiencia -más allá de lo textual e hipertextual- para redes sociales o de otro tipo de estrategias de contenidos para captar nuevos perfiles o fidelizar usuarios, o los recursos y perfiles profesionales implicados en ello. También se recabó su visión acerca de los resultados logrados, las posibilidades y dificultades, internas y externas, para el desarrollo de estas prácticas y los posibles planes futuros sobre innovación editorial en redes. Con ello, además de cubrir deficiencias de la observación inicial (triangulación), se buscó obtener información adicional (complementación) desde la perspectiva de la planificación estratégica e innovación empresarial.

3. Observación y documentación sobre casos significativos de innovación editorial en redes sociales detectados en fases anteriores. Sobre la base de datos inicial, entre enero y marzo de 2021, se prestó especial atención a los contenidos visuales, audiovisuales, sonoros e interactivos multimedia de canales en red (tanto los publicados/disponibles desde la web como los creados/publicados en redes sociales externas) de los verificadores y se recogieron sus características. Se consideraron aspectos tales como su idioma, temática, enfoque/tono, formato y aspectos formales (referidos a las prácticas empleadas por los verificadores, el tipo de comunicación, alfabetización mediática...) o utilidad para las audiencias (esto es, el modo en el que los usuarios pueden acceder a los contenidos a través de los distintos formatos e iniciativas ofrecidos por los verificadores). Por último, se elaboró una relación de contenidos innovadores sobre verificación atendiendo a dichos aspectos. El muestreo de contenidos fue intencional, buscando garantizar la cobertura de distintas plataformas de social media de los verificadores, y sin filtrarlos por temática. Consideramos con ello que se recogen los casos más significativos. La mayoría de los contenidos analizados están vinculados directa o indirectamente a la pandemia de la Covid-19 y sus consecuencias (por el periodo de análisis). También se incluyen otros relacionados con: la realización del proceso de verificación, consejos para combatir la desinformación o contenidos de carácter divulgativo.

Tabla 1. Datos básicos de proyectos analizados y entrevistas realizadas

\begin{tabular}{|c|c|c|c|}
\hline Nombre del verificador & País & Tipo de verificador & Persona entrevistada \\
\hline AFP Factual & Argentina/ España & Sección & $\begin{array}{l}\text { Anella Reta (editora del } \\
\text { fact-checking) }\end{array}$ \\
\hline Agencia Lupa & Brasil & Medio & - \\
\hline Agencia Ocote & Guatemala & Sección & $\begin{array}{l}\text { Alejandra Gutiérrez } \\
\text { (directora y coord. editorial) }\end{array}$ \\
\hline Animal Político (El Sabueso) & México & Sección & $\begin{array}{l}\text { Tania Montalvo (editora gene- } \\
\text { ral) }\end{array}$ \\
\hline Aos Fatos & Brasil & Medio & - \\
\hline Bolivia Verifica & Bolivia & Medio & - \\
\hline Chequeado & Argentina & Medio & $\begin{array}{l}\text { Laura Zommer (directora eje- } \\
\text { cutiva y periodística) }\end{array}$ \\
\hline Colombia Check & Colombia & Medio & - \\
\hline Convoca & Perú & Sección & - \\
\hline Cotejo.info & Venezuela & Medio & - \\
\hline Ecuador Chequea & Ecuador & Medio & Erika Astudillo (editora) \\
\hline EFE Verifica & España & Sección & Desireé García (responsable) \\
\hline
\end{tabular}


RLCS, Revista Latina de Comunicación Social, 80, 135-161

[Investigación] https://www.doi.org/10.4185/RLCS-2022-1535| ISSN 1138-5820 | Año 2022

\begin{tabular}{|l|l|l|l|}
\hline Efecto Cocuyó & Venezuela & Sección & - \\
\hline El Surtidor & Paraguay & Sección & - \\
\hline Estadão Verifica & Brasil & Sección & - \\
\hline La Nación & Argentina & Sección & - \\
\hline La Silla Vacía & Colombia & Sección & - \\
\hline La Voz de Guanacaste & Costa Rica & Sección & $\begin{array}{l}\text { Gabriela Brenes } \\
\text { (directora ejecutiva) }\end{array}$ \\
\hline Maldita (Maldito Bulo) & España & Sección & $\begin{array}{l}\text { Clara Jiménez } \\
\text { (cofundadora y codirectora) }\end{array}$ \\
\hline Newtral & España & Medio & $\begin{array}{l}\text { Joaquín Ortega } \\
\text { (responsable de contenido) }\end{array}$ \\
\hline Observador & Portugal & Sección & - \\
\hline Ojo Público (Ojo biónico) & Perú & Sección & $\begin{array}{l}\text { David Hidalgo (director de } \\
\text { noticias) }\end{array}$ \\
\hline Periodismo de barrio & Cuba & Sección & - \\
\hline Polígrafo & Portugal & Medio & - \\
\hline Salud con Lupa (Comprueba) & Perú & Medio & $\begin{array}{l}\text { Fabiola Torres (directora } \\
\text { co-fundadora) }\end{array}$ \\
\hline Spondeo Media & México & Medio & - \\
\hline Verificado & Uruguay & Medio & $\begin{array}{l}\text { Syndy García } \\
\text { (periodista fact check) }\end{array}$ \\
\hline Verificador de La República & Perú & Sección & $\begin{array}{l}\text { Irene Ignacio } \\
\text { (coordinadora de contenidos) }\end{array}$ \\
\hline Alba Tobella (codirectora)
\end{tabular}

Fuente: Elaboración propia.

\section{Resultados}

\subsection{Coordenadas y estrategias de difusión básicas en red: canales y audiencias}

Más de la mitad de los verificadores analizados dispone de redes sociales propias. Todos tienen canal en Twitter, red oficial de la IFCN y donde se concentra la mayoría de las audiencias. Según datos recogidos a finales de febrero de 2021 sobre sus propios canales, prácticamente todos los medios superan los 15.000 seguidores, y hay casos que rondan (Newtral, con 186,3 mil y Agencia Lupa, con 184,6) e incluso superan (Aos Fatos, 246,9 mil, Chequeado con 298,5 mil y Maldita, que entre el perfil de Maldito Bulo y el general sobrepasa los 400.000 usuarios) los 200.000. Cuentan también con página en Facebook, dirigida ésta, según sus promotores, a un público de mediana edad o edad más avanzada que no está presente en otras redes. Las propias secciones o unidades de verificación, que para otras redes comparten espacios con el medio matriz, disponen también de canales propios en Twitter y Facebook (ver tabla 2 en anexos). Linkedin está también presente en el 21\% de casos, orientada, además de a compartir ciertos contenidos de verificación, a la comunicación corporativa y al networking entre periodistas y verificadores.

Redes sociales audiovisuales de uso extendido como YouTube e Instagram forman parte también de la presencia digital de muchos verificadores. Mientras la primera se concibe más como un repositorio 
desde el cual las audiencias visualizan contenido, Instagram se presta a mayor interacción y tiene grandes comunidades de seguidores (147k Agencia Lupa; 79k Aos Fatos, 38,2k Newtral, 30,3k Maldita o 28,4k Polígrafo). La práctica totalidad de plataformas independientes tiene presencia en al menos una de las dos, y el 60\% de medios con secciones de verificación dispone también de canales en éstas donde se publican contenidos vinculados a fact checking.

En estos y otros canales compartidos con el medio, las secciones o unidades de verificación desarrollan algunas estrategias para segmentar y facilitar el acceso directo a los contenidos sobre su labor. Por ejemplo, en la mayoría los posts sobre chequeos se diferencian visualmente del resto porque van acompañados de imágenes con textos que corresponden al resultado del chequeo (verdadero, falso, etcétera) y de hashtags, a veces fijos, como \#elVerificadorLR en el Verificador de La República, que además de canales propios en Twitter y Facebook se apoya en los del medio en éstas y otras redes. Otras estrategias son la creación de listas de reproducción de vídeos sobre verificaciones en perfiles genéricos de YouTube, como La Voz Chequea, Convoca Verifica o Efe Verifica, o la utilización de las historias destacadas en Instagram para compartir secciones de bulos o dar accesos a contenidos de diverso formato, como el podcast "Chequeo en lenguas” de Ojo biónico.

Algunos verificadores (20\%) cuentan con canales de podcasting en Spotify y similares, sin cifras masivas de seguidores porque actúan sobre todo como repositorios. En casos concretos localizamos canales secundarios en Pinterest, Flickr, Dailymotion o Flipboard. Medios como Maldita o Newtral van un paso más allá en cuanto a presencia digital, con canales y elevado número de seguidores en TikTok y Twitch respectivamente, desde donde generan contenidos dirigidos a audiencias más jóvenes.

\subsection{Flujo de información y función de cada red: entre la mera difusión y la generación de con- tenidos ad hoc}

Explorando los contenidos visuales y multimedia publicados por las plataformas analizadas en redes sociales como Twitter, Facebook o Linkedin en comparación con los que, en sus espacios web, acompañan a textos vinculados a verificación (imágenes, vídeos, etc.), se aprecia que en muchos casos son idénticos. Hacen a lo sumo ciertas adaptaciones en cuanto a tamaño y otros parámetros básicos para cada red social, con hipervínculos a la información completa. Estas redes se emplean fundamentalmente para ampliar la difusión de estas publicaciones, generar tráfico hacia sus websites y buscar interacción con los usuarios.

Redes sociales de video como YouTube y otras de podcasting se usan como repositorios donde subir y publicar contenidos innovadores elaborados offline, a veces seriados o agrupados por listas o series según su tipología o la iniciativa a la que correspondan. Estos contenidos son también difundidos en forma de posts o tweets en redes sociales como Twitter, Facebook o Linkedin, que aglutinan mayores audiencias, y distribuidos con enlace o código embebido desde sus webs, bien de forma individual acompañando a determinados artículos o bien como colección a través de micrositios monográficos. En casos como La Silla Vacía, Observador, Ojo Público o Polígrafo, se integran también newsletters periódicos que reciben ciertos grupos de suscriptores. Además, son varios medios quienes, al ser entrevistados, resaltan su utilidad como recursos de apoyo para atender las consultas o demandas de verificación que determinados usuarios remiten, vía WhatsApp o sistemas de mensajería privada de redes sociales.

Por último, cabe destacar el uso de algunas redes sociales que cuentan con su propia comunidad y se etiquetan como herramientas desde las cuales se generan contenidos nativos a través de estrategias autónomas. Sería el caso de Instagram, donde además de posts más similares a los de otras redes, verificadores como Chequeado usan las historias destacadas para incluir contenidos interactivos o retransmisión en directo sobre verificación. De igual forma, desde Twitch y TikTok, Newtral y Chequeado, respectivamente, vienen realizando streaming y videos informales y en tono de humor a los que superponen emoticonos, gifs animados y otros grafismos.

\subsection{Formato, temática y enfoque de contenidos sobre verificación online: catálogo de prácticas}

En cuanto a formatos, y como se ha adelantado, predominan los recursos tipo imagen, junto a los au- 
diovisuales y sonoros. Por otro lado, escasean las visualizaciones de datos, especialmente las interactivas/multimedia, que aparecen principalmente en las redes sociales de verificadores más orientados al periodismo de datos y con perfiles especializados.

Entre los contenidos en redes vinculados directa o indirectamente a la pandemia de la Covid-19 y sus consecuencias, encontramos distintos enfoques. Abundan contenidos extensos sobre el proceso de verificación, a modo de explainers en diversos formatos, basados en el slow journalism y en el periodismo explicativo. Y al otro lado son también frecuentes contenidos sintetizados o curados basados en el potencial de la comunicación en red, como infografías o píldoras de resumen en vídeo. Ambas tipologías tienen un enfoque divulgativo y didáctico. También localizamos información de servicios (pautas para prevenir la Covid-19, cómo funcionan las vacunas, etcétera), junto a consejos para detectar noticias falsas y explicaciones para prevenir la desinformación en salud.

El Sabueso @ElSabuesoAP.25 mar.

Medir el nivel de oxigenación es muy importante ante un posible contagio de \#COVID-19. Recuerda, la pandemia continúa, por eso aquí te explico más sobre el oxímetro y cómo usarlo. animalpolitico.com/elsabueso/oxim...

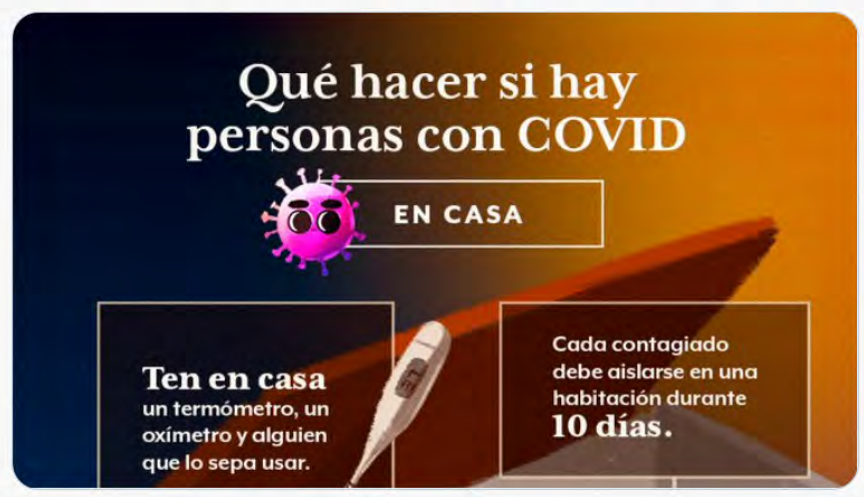

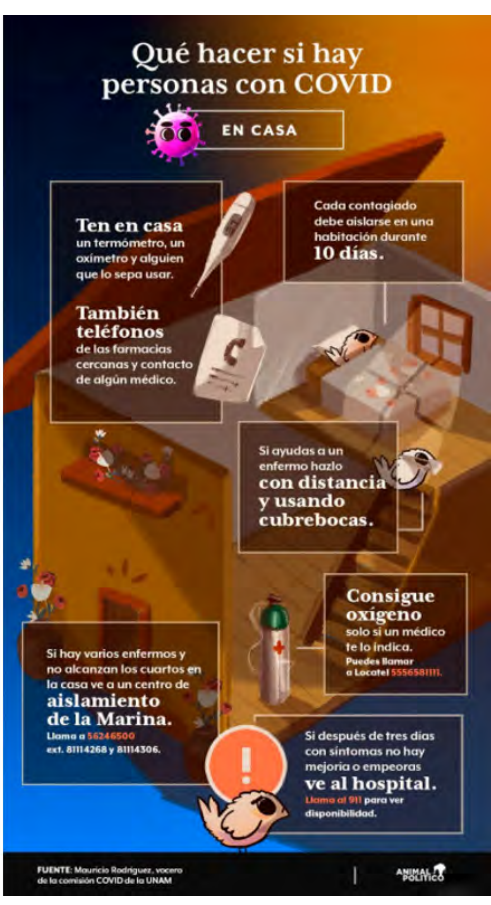

Figura 1: Infografía sobre la importancia de oxigenar ambientes ante la Covid-19 publicada por El Sabueso de Animal Político en Twitter en febrero de 2021.

Fuente: https://bit.ly/3lXgPvd

Casi siempre se publican en español, con la excepción de Verificat, también en catalán en el momento del análisis, y de otros medios que, para atender la diversidad cultural de sus territorios y alfabetizar a determinadas minorías étnicas, realizan versiones traducidas de éstos. Es el caso de Ecuador Chequea con vídeos de chequeos en directo, resúmenes de verificaciones, etc., subtitulados a kichwa y compartidos en redes sociales como Facebook para estos segmentos de población, o del podcast apoyado con ilustraciones e imágenes en movimiento "Chequeo en lenguas" de Ojo Biónico en YouTube, autodefinido como "verificación sobre el Covid-19 para pueblos indígenas".
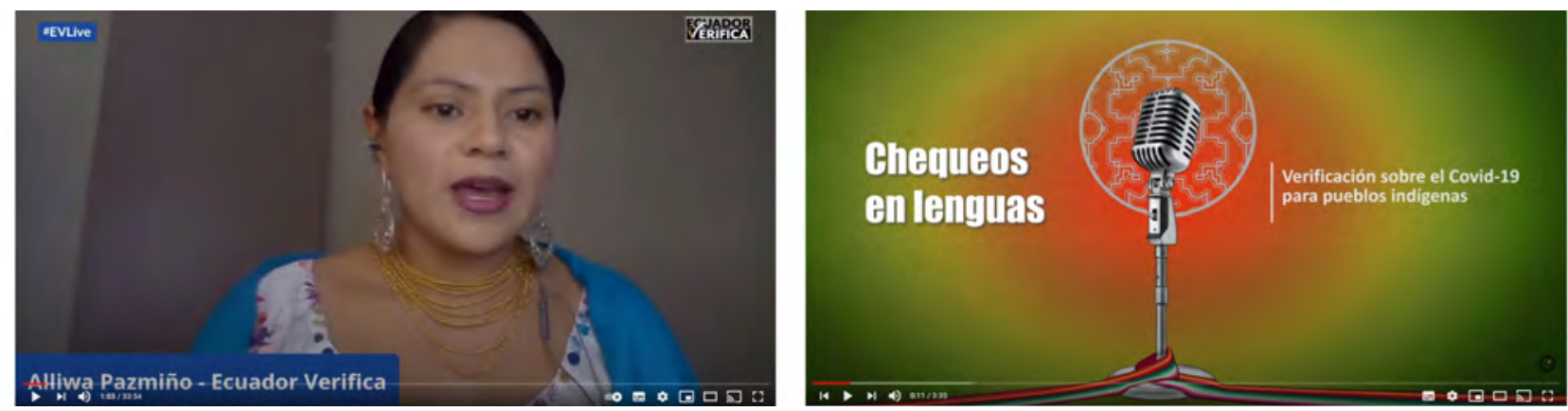
Figura 2: Ejemplos de vídeo en directo en lengua indígena, vía YouTube de Ecuador Verifica y de versión en shipibo-konibo de chequeo, vía YouTube de Ojo Público, respectivamente.

Fuentes: https://bit.ly/3m3Sjsb y https://bit.ly/39m1kI5

A continuación se comparte, a modo de catálogo o taxonomía no exhaustiva según su finalidad o utilidad ciudadana, algunos tipos de contenidos visuales, interactivos o multimedia que los verificadores analizados vienen publicando en sus redes sociales y espacios online.

1. Anuncios visuales del resultado de chequeos o de reportajes explicativos. Nos referimos a composiciones fotográficas con la imagen del protagonista u objeto representativo de la supuesta información, a la que se superponen normalmente, como adelantamos, el término correspondiente, a modo de etiqueta, al resultado del fact check según la escala del medio y, en ocasiones, un titular o texto complementario explicativo, un hashtag y el logotipo del verificador. Este tipo de contenidos está presente en la práctica totalidad de casos analizados. Algunos verificadores también incluyen en sus redes banners de explainers visuales, de formato similar, para promocionar sus artículos explicativos (el caso, por ejemplo, de Maldita a través de su sección "guías” de sus historias destacadas de Instagram y otras redes).

2. Posters gráficos/ infográficos con información de servicio o consejos ciudadanos de salud ante la pandemia. De distinta extensión o profundidad, son distribuidos a través de Twitter (el ya comentado caso de El Sabueso de Animal Político), Instagram (Bolivia Verifica), u otras redes sociales según los casos. Son composiciones donde la información visual -con gráficas, ilustraciones o iconos vectoriales, a veces tomados de la web y otras elaborados ad hoc por el medio- predomina sobre la textual, que actúa como mero complemento.
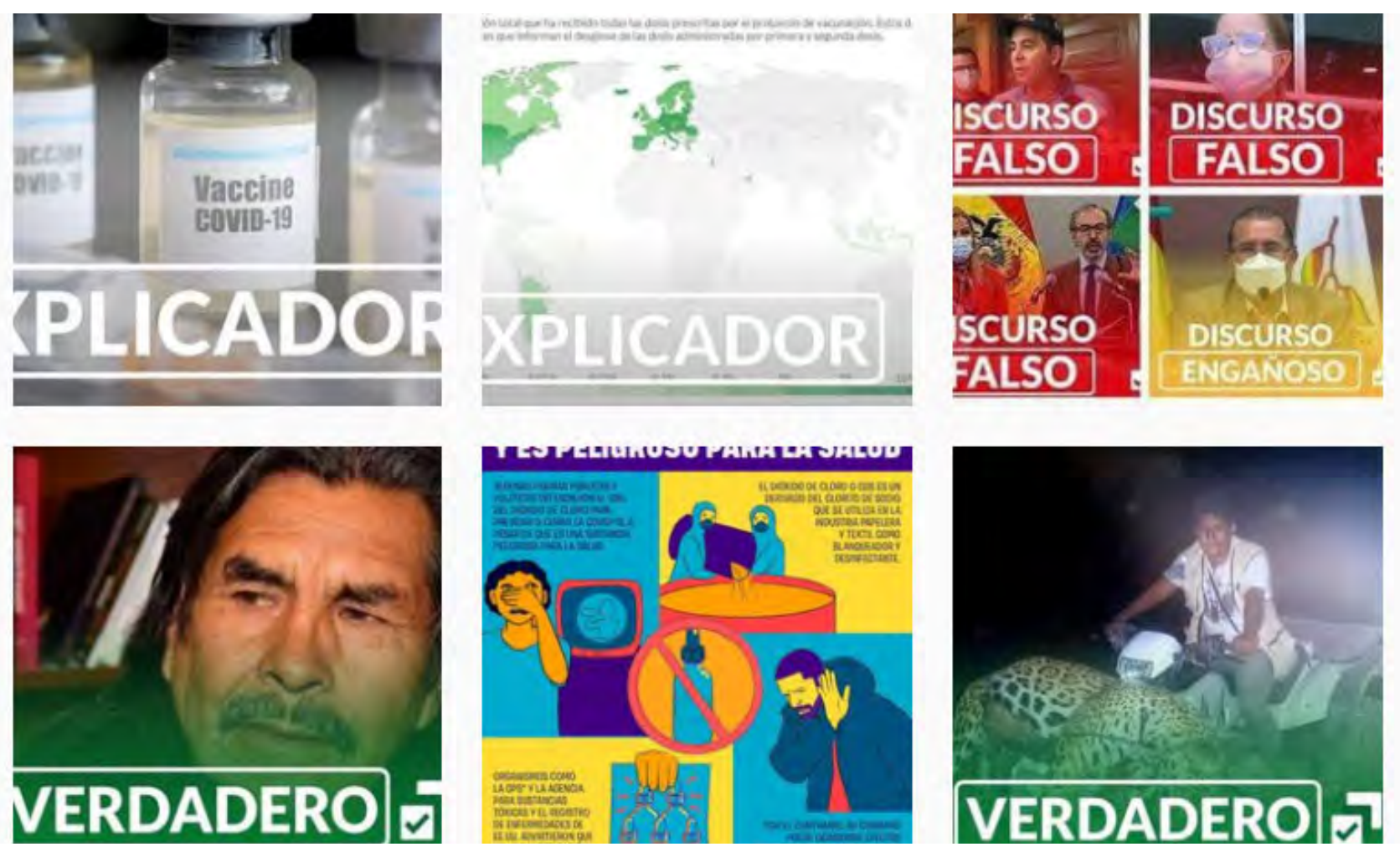

Figura 3: Extracto del perfil de Bolivia Verifica en Instagram, donde se combinan contenidos de las dos primeras tipologías señaladas.

Fuente: $\underline{\text { https://www.instagram.com/boliviaverifica }}$

3. Video-resúmenes periódicos de verificaciones. Sería el caso del ya comentado resumen semanal en vídeo de Ecuador Chequea vía YouTube, con versión traducida a kichwa y bastante repercusión en redes sociales como Facebook según sus promotores, y otros que funcionan como alternativa a los newsletters regulares que medios como Salud Verifica envían a sus suscriptores. 


\section{ECUADOR
VERIFICA}

\section{En colaboración con $(T)$ into}

$0: 06 / 2: 09$

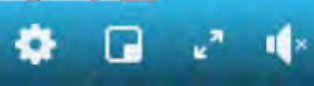

Figura 4: Resumen semanal de verificaciones en vídeo vía Facebook de Ecuador Verifica.

Fuente: https://fb.watch/4tSn8PFwCP/ (ver también YouTube: https://bit.ly/3ct7hEU)

4. Podcasts sobre verificación. Junto a los contenidos audiovisuales son los más frecuentes, como se anticipó. Algunos medios le dan un uso similar al de los citados video-resúmenes, como Maldita con su "Maldita la hora", podcast pionero semanal (con más de 70 capítulos) de 10-15 minutos sobre bulos, datos y hemeroteca que emite los viernes vía Ivoox, iTunes y Spotify, y se anuncia también en sus redes con la etiqueta \#malditalahora. Encontramos, además, otros de diversa naturaleza, por ejemplo, "audios anti-desinformación” dentro de las listas de reproducción de Chequeado en YouTube; "Podcast verifica" de Agencia Lupa, lanzado en 2019, pionero en Brasil y accesible desde una de sus listas de reproducción de YouTube y desde Spotify; podcasts con consejos sobre la Covid-19 de salud de Ecuador Chequea en Anchor; o "Chequeo amplificado", alojados en la plataforma Speaker y accesibles desde una sección de la web de Colombia Check.

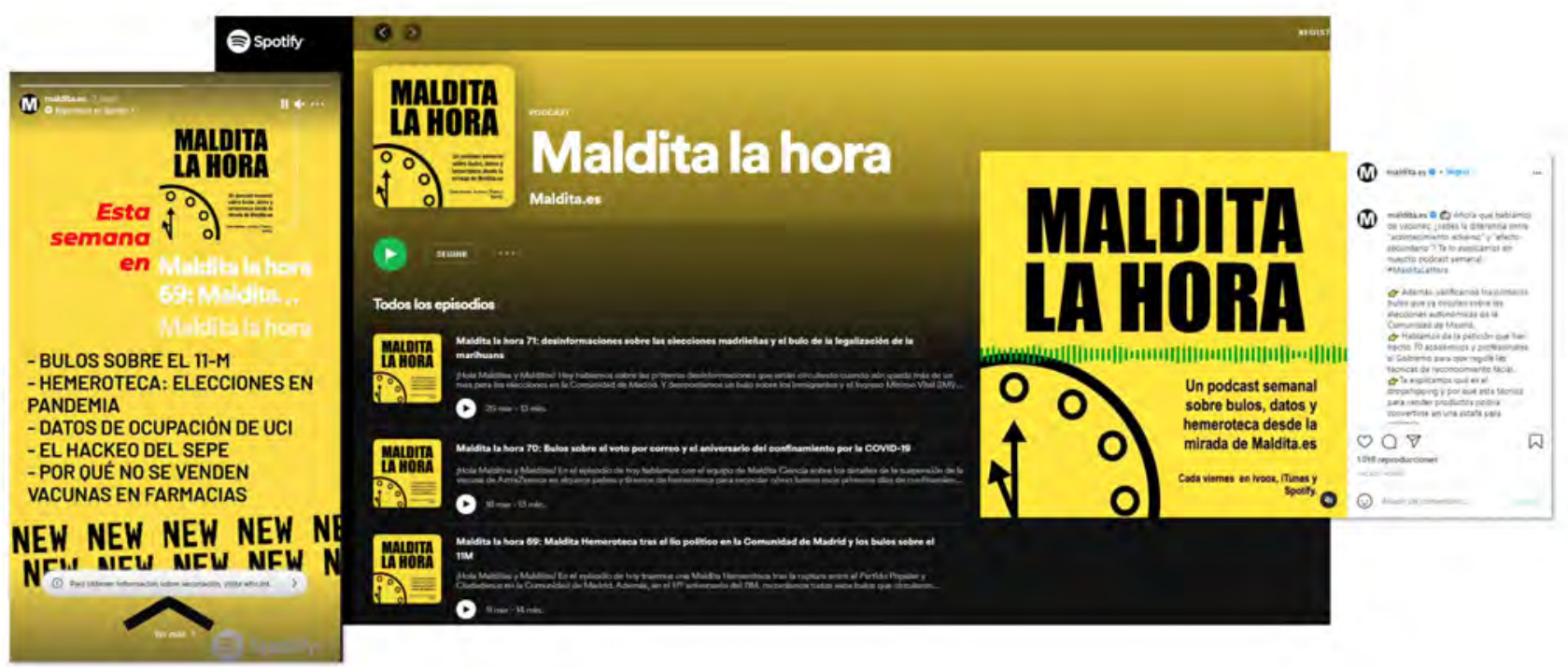

Figura 5: Publicaciones sobre \#malditalahora en Instagram de Maldita, vía historia y post (en laterales), que da acceso al mismo en Spotify (en el centro).

Fuentes: https://www.instagram.com/maldita.es/ y https://spoti.fi/3u76QX3 


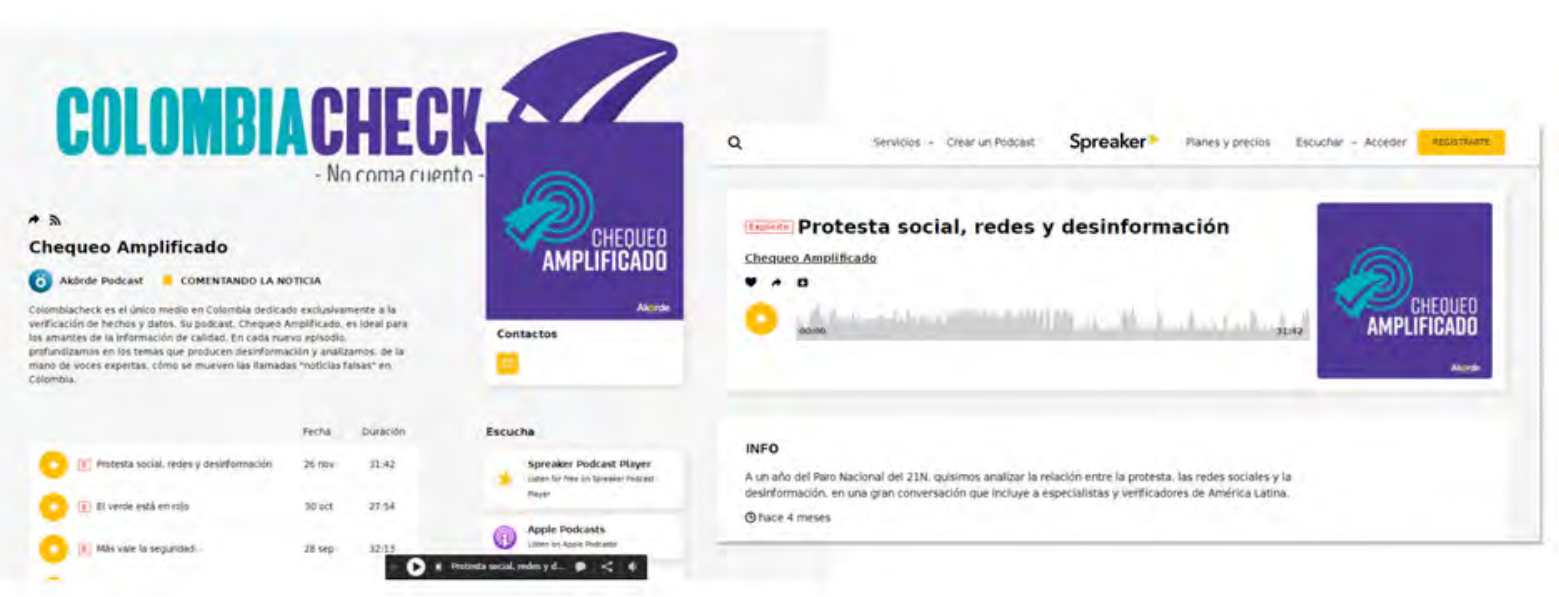

Figura 6: Extractos del canal de podcasts "Chequeo Amplificado" en Speaker de Colombia Check.

Fuente: https://www.spreaker.com/show/colombia-check

5. Audio-resúmenes de verificación. Como especie de combinación de las dos tipologías anteriores, determinados verificadores, como Ojo Biónico de Ojo Público, han desarrollado este formato, explicaciones de 1 minuto en audio de sus informes de verificación que suben a SoundCloud e insertan en sus artículos. Su objetivo, según comentaba su director de noticias, David Hidalgo, es que la gente pueda compartirlos por WhatsApp y, con ello, contrarrestar la desinformación incluso en las zonas menos expuestas a redes sociales.

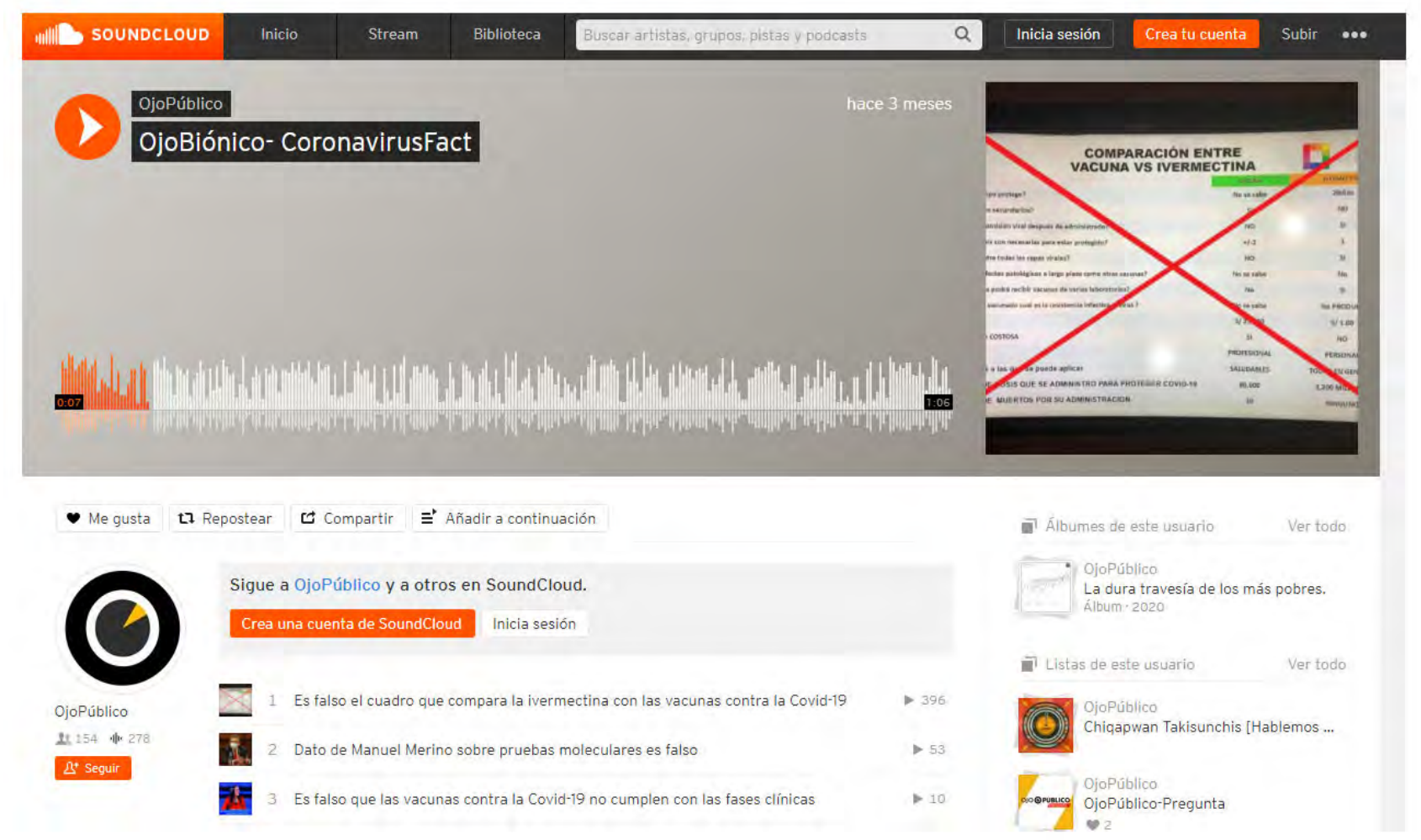

Figura 7: Podcast de 1 minuto sobre verificaciones sobre coronavirus de Ojo Público.

Fuente: https://soundcloud.com/ojopublico/sets/podcast-ojo-bionico

6. Vídeo-entrevistas/ testimonios en vídeo de expertos sobre fact-checking. Es el caso también, por ejemplo, de Ojo Público, que ofrece en sus redes sociales colecciones de vídeos donde expertos en verificación -muchos periodistas de otros verificadores- explican ante la cámara conceptos básicos sobre desinformación o comparten experiencias realizadas para divulgar sobre la importancia del fenómeno y sus consecuencias. 


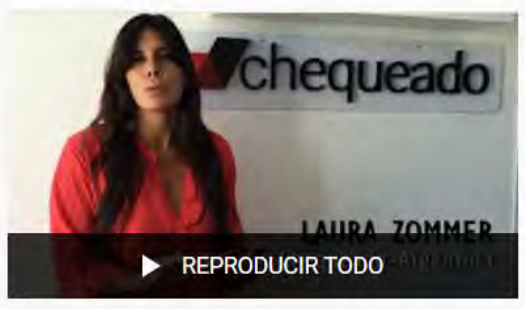

Fact-Cheking

12 vídeos $\cdot 99$ visualizaciones · Actualizado por última vez el 20 jul 2020

$\equiv+x \rightarrow \cdots$

OjoPúblico

\section{SUSCRIBIRME}

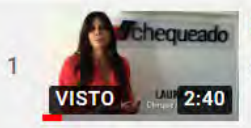

El factchecking según: Laura Zommer, directora de Chequeado OjoPúblico

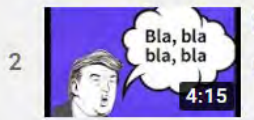

El factchecking según: Antonio Cucho, Univisión Noticias OjoPúblico

\section{ABABEMOS BONLS}

OIIBLAS 데 0:43

Fact-checking: Por la boca muere el pez - Segunda Edición OjoPúblico

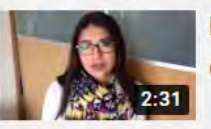

El factchecking según: Tania Montalvo, periodista de El Sabueso OjoPúblico

5

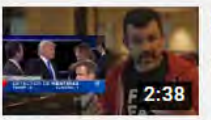

El factchecking según: Rony Rojas, director de El Detector de Mentiras ojopúblico

Figura 8: Vídeos de la colección “Fact-Checking” de Ojo Público en su canal de YouTube.

Fuente: https://bit.ly/31pcF5R

7. Vídeo-explainers con periodistas ante la cámara. De distinta duración, entre los más extensos se sitúan los de El Sabueso de Animal Político, de unos 8 minutos, donde explican por qué algo es verdadero o falso e introducen, en medio, "chistes, detalles, etc. para enganchar al público", según contaba Tania Montalvo. Las narrativas y el tono también varían, dependiendo tanto del medio como de la red social. El abanico iría de vídeos más convencionales, como los de EFE Verifica en YouTube, apoyados por diagramas explicativos e imágenes de actualidad fijas o en movimiento, hasta otros más dinámicos o disruptivos, como "what the fake" de Newtral en YouTube, con música y ejemplos de desinformación sobre la pandemia (en ocasiones, también a modo de resumen semanal), o los de Maldita y Chequeado en YouTube e Instagram. Algunos están más elaborados, mientras que otros son menos sofisticados técnicamente, como "al grill-datos y más datos" de Ecuador Chequea en YouTube, con cifras ante la cámara y montaje a base de texto y efectos sonoros. Los hay rodados en plató, más próximos al formato educativo propio de los MOOCs originarios, y en exteriores y con luz natural, a modo de crónicas/reportajes visuales.

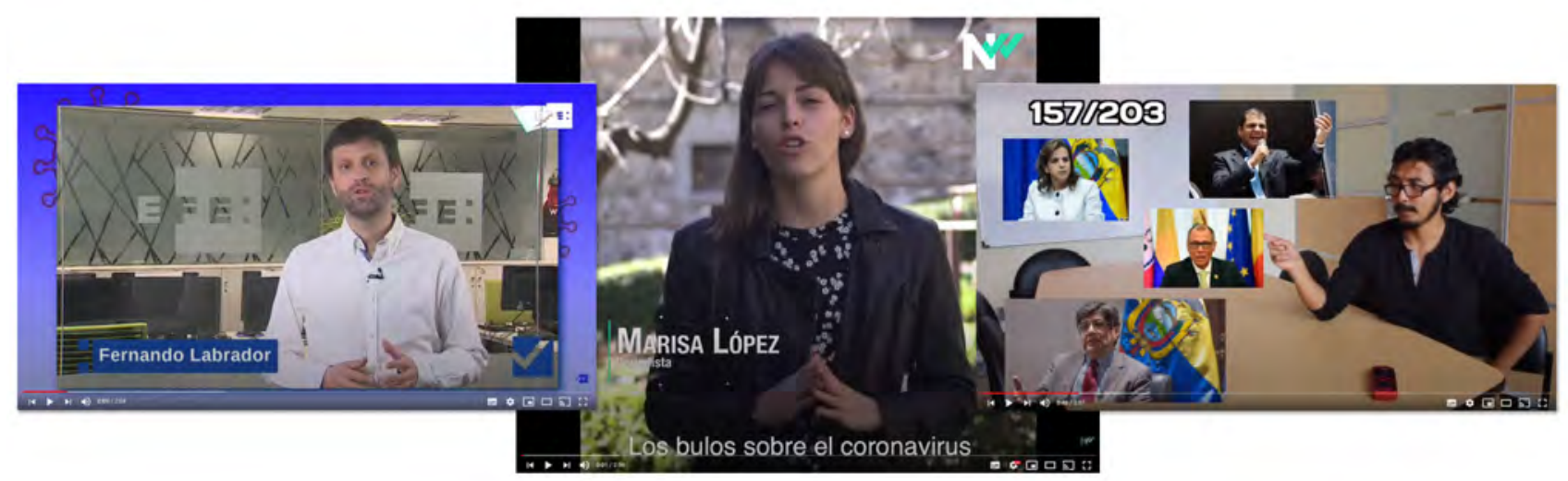

Figura 9: Ejemplos, respectivamente, de vídeos de EFE Verifica en YouTube de la agencia, con el redactor ante la cámara (práctica poco habitual en EFE); de la sección "what the fake" de Newtral; y de "all grill-datos y más datos" de Ecuador Chequea.

Fuentes: https://bit.ly/3crvg7A, https://bit.ly/3w7kDP6 y https://bit.ly/3w6wtsC

8. Streaming sobre verificación. Una variedad de los anteriores serían las emisiones en directo, a cargo también de profesionales ante la cámara, que realizan determinados medios a través de redes 
sociales como YouTube (Ecuador Verifica), Instagram (Chequeado) e incluso Twitch (Newtral). Si bien en este último caso se trata de entrevistas informales a personajes vinculados al mundo Youtuber (“charlando con...”) o crónicas de actualidad política que no siempre se relacionan directamente con fact-checking, resulta significativo por su carácter pionero y por cómo se han apropiado de la atmósfera y formato propios del streaming.
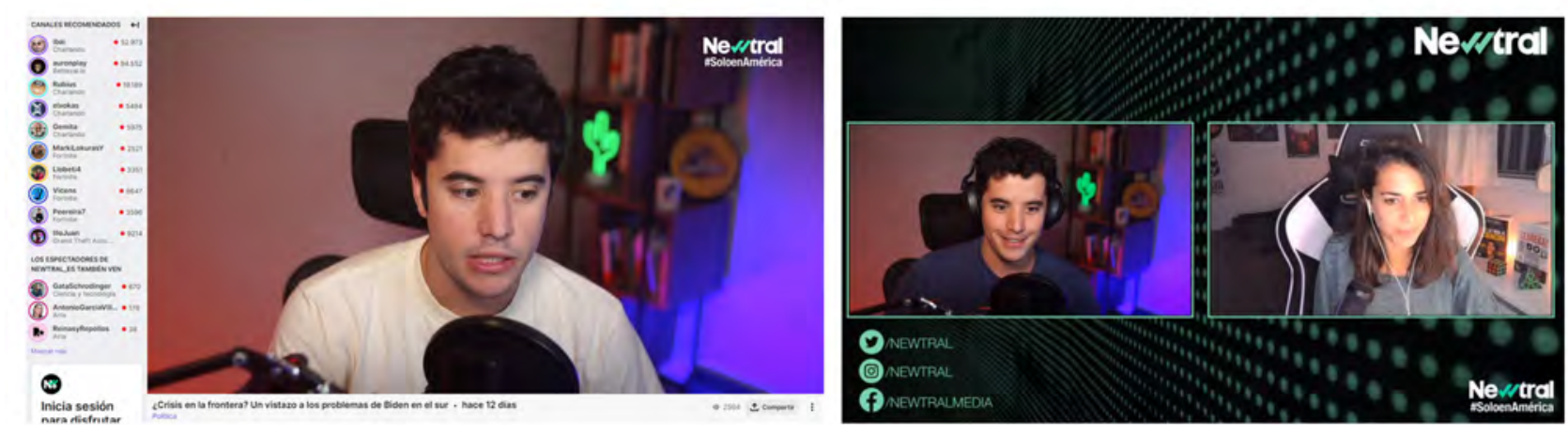

Figura 10: Ejemplos de grabaciones de retransmisiones de Newtral vía Twitch.

Fuente: https://www.twitch.tv/newtral es

9. Video-animaciones o video-presentaciones diversas. Es el caso de las "Cápsulas de verdad” de Bolivia Verifica en YouTube, donde muñecos animados sustituyen a los periodistas y se mezclan animaciones e imágenes reales, con voz en off de periodistas sobre verificaciones de actualidad, o de las video-guías con información útil relacionada con la Covid-19 de Ecuador Chequea en su YouTube, elaboradas con aplicaciones como Powtoon.
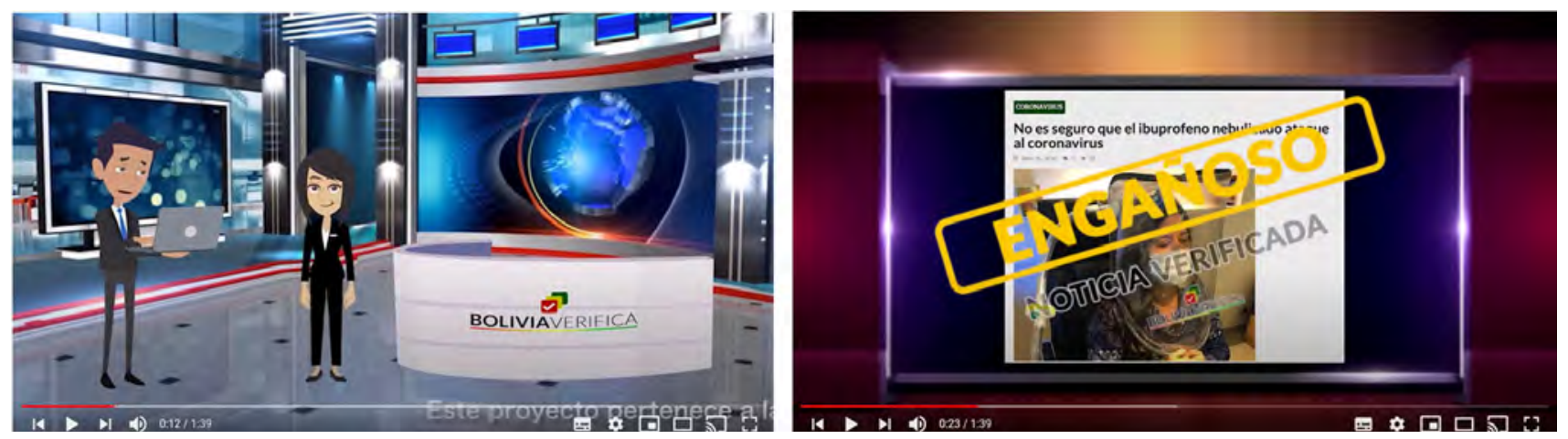

Figura 11: Extractos de vídeo de la lista “Cápsulas de la verdad” de Bolivia Verifica.

Fuente: https://bit.ly/2PzbfD2

10. Video-montajes y otros video-contenidos creativos, divertidos e incluso gamificados. Las fórmulas aquí son diversas. Algunos ejemplos serían los vídeos de Maldita en TikTok, de ritmo ágil, con jóvenes ante la cámara y música, efectos, superposiciones y gifs animados, o \#verifiquenvagos de Colombia Check en YouTube, basados en el humor e ingenio para, según sus promotores, desmentir desinformaciones del coronavirus en redes sociales.
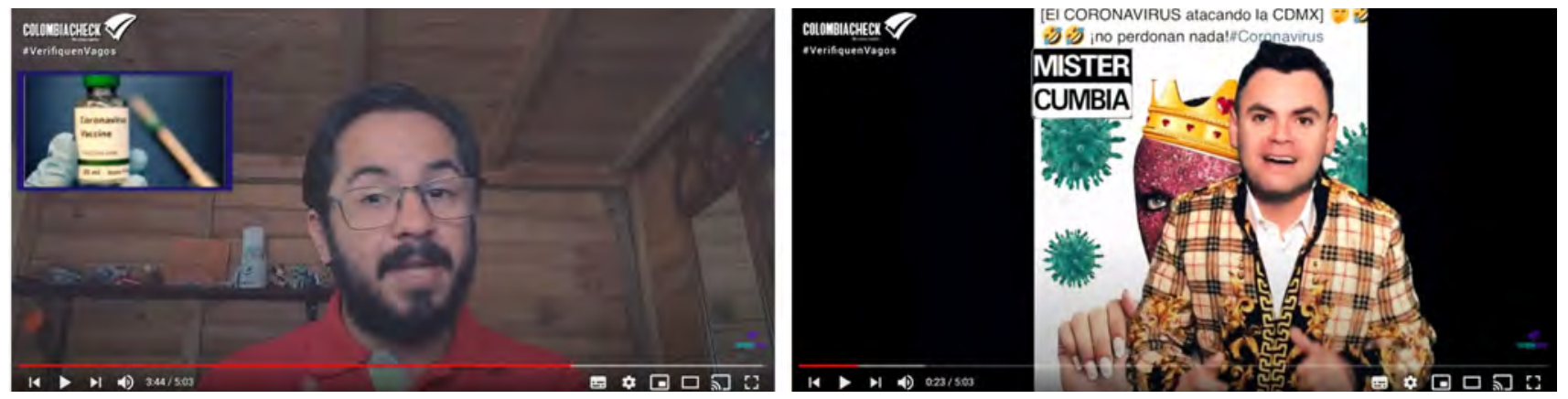

Figura 12: Fragmentos de \#verifiquenVagos de Colombia Check, sobre "los fakes del coronavirus".

Fuente: https://bit.ly/3czRZ1v 
11. Contenidos ficcionados seriados. Entre ellas, los cómics en formato de póster en historias destacadas de Instagram de Salud con Lupa; o los vídeos seriados de verificación de la Agencia Lupa, a modo de cortometrajes periódicos que también usan el humor y la cultura del meme para enganchar a las audiencias y se subtitulan en distintos idiomas.
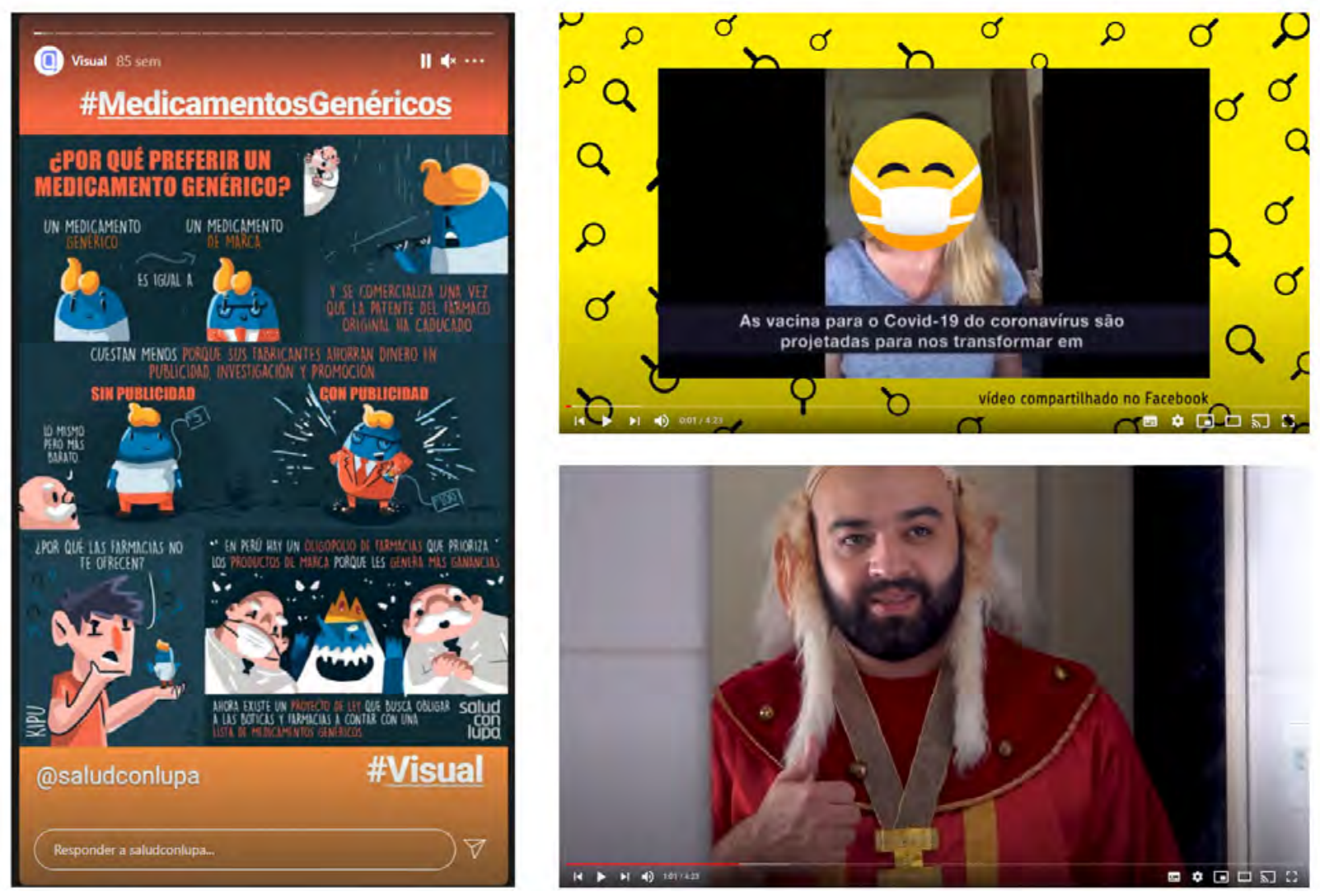

Figura 13: Uno de los pósters tipo cómic del apartado “visual” de historias destacadas del Instagram de Salud con Lupa (izquierda) y “\#SóQueNão, Ep. 03 - Vacinas e mutação genética” (diciembre de 2020), vía YouTube de Agencia Lupa (derecha).

Fuente: https://bit.ly/2P7doWU y https://bit.ly/3w2B4fH

12. Música contra la desinformación. Hay quienes van más allá y emplean géneros musicales populares en sus territorios para difundir la verificación y que la gente comente sobre ello. Es el caso de los vídeos sobre rap/ hip-hop de Ojo Público, que incluso tiene previsto lanzar durante 2021 un disco con una selección de temas interpretados por artistas urbanos que advierten, en lenguas originarias, los daños que causa la desinformación en el país.
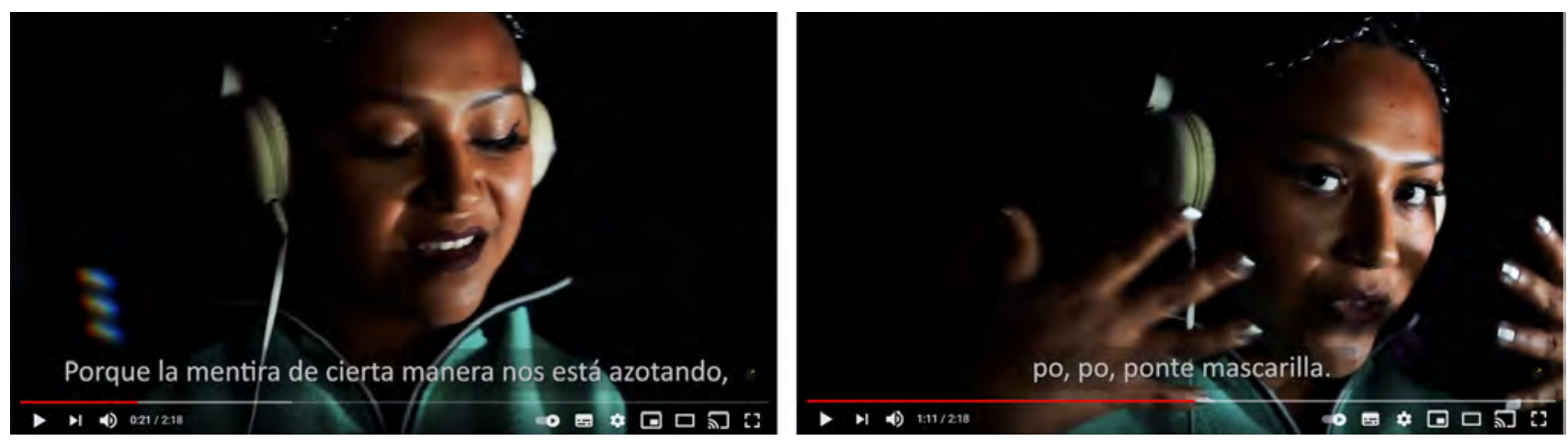

Figura 14: “Realismo”, interpretado por La Torita, tercer sencillo del disco de rap ‘Chiqapwan Takisunchis’ [Hablemos con la verdad], producido por Ojo Público, vía YouTube.

Fuente: https://bit.ly/3lXQD3s 
13. Visualizaciones interactivas sobre verificación. Son frecuentes, entre otros, en Newtral y Verificat, que usa Flourish para su web y las adapta para historias y posts en Instagram, red en la que también la Agencia Lupa dedica, en sus stories destacadas, una sección, “Sabías qué”, a explicar con cifras datos de actualidad.

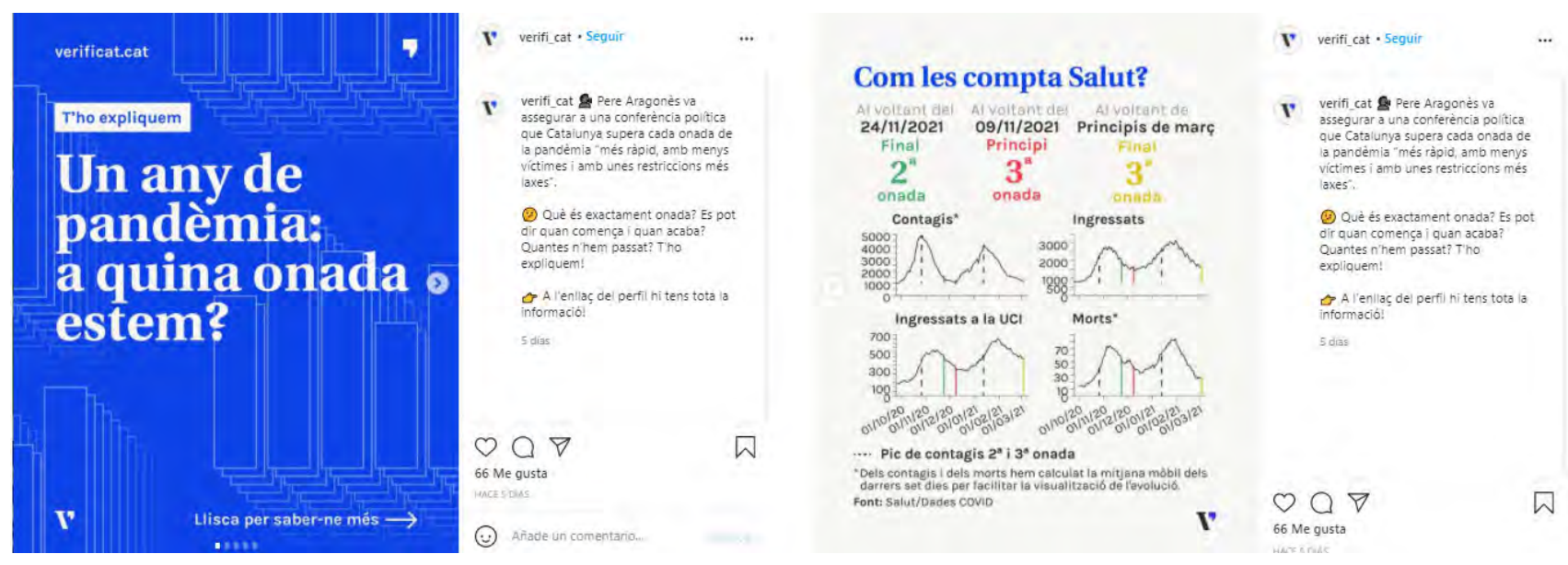

Figura 15: Algunas de las imágenes de un post de Instagram de Verificat sobre la pandemia.

Fuente: https://bit.ly/3wfQsFF

14. Sondeos, encuestas y otras opciones interactivas sobre verificación. Algunos medios (Maldita, Chequeado, etc.) usan las historias destacadas de Instagram para producir quizs, juegos u otros contenidos interactivos ad hoc sobre esta red social.
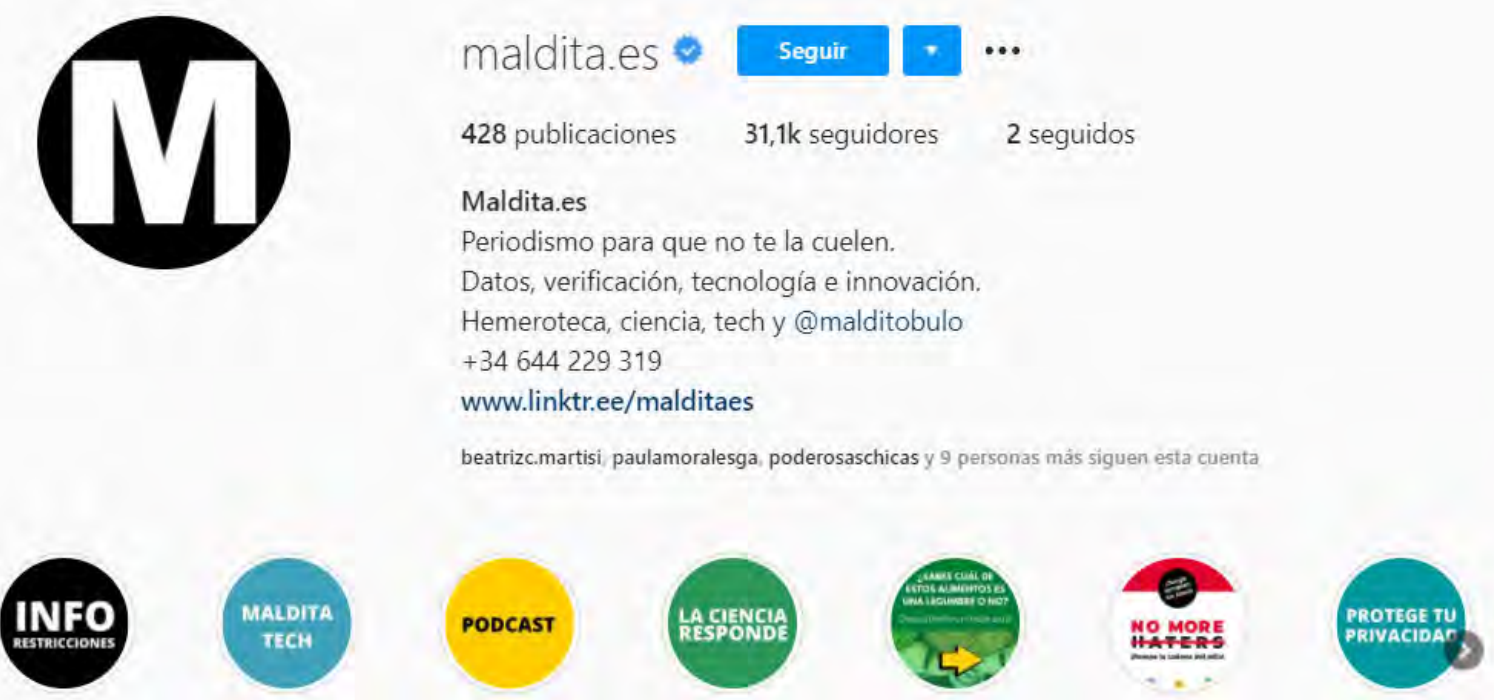

Figura 16: Detalle de historias destacadas, con Quiz, encuestas... de Maldita en Instagram.

Fuente: https://www.instagram.com/maldita.es/

15. Especiales interactivos difundidos también en redes sociales. Además de las citadas tipologías, que suceden con cierta frecuencia o periodicidad, hallamos también interesantes monográficos sobre verificación, de naturaleza visual o interactiva, desarrollados por algunos verificadores como parte de su estrategia de producción y difundidos también en sus redes sociales, según comentamos más adelante.

\subsection{Recursos y procesos para la creación de contenidos para redes sociales}

Buena parte de la citada tipología de contenidos implica un tiempo de producción, de ahí que estas prácticas estén más limitadas en los verificadores que son micromedios. Su realización corre a cargo, 
dependiendo de los casos, de personal propio de los verificadores (con dedicación exclusiva o no), o de externos o colaboradores esporádicos. En varios verificadores analizados cuentan con expertos en visualización (por ejemplo, Verificat, Newtral o Maldita) y/o diseñadores que "grafican" los datos (por ejemplo, Ecuador Chequea) en sus equipos. El número de trabajadores varía, y hay verificadores pequeños, con 4-10 periodistas, como Cotejo.info o EFE Verifica, y otros como Bolivia Verifica o La Silla Vacía donde la plantilla asciende a 20-35 personas. En medios pequeños o secciones de verificación, los propios redactores ejercen casi siempre de community manager, y algunos como La Voz de Guanacaste tienen editores de audiencias como figuras esenciales para la escucha activa de sus canales en red.

Algunas iniciativas son posibles mediante sinergias entre medios, colaboraciones externas o gracias a la disponibilidad de grants o financiación externa para su producción. Es el caso de \#Latinográficas de El Surtidor, proyecto de periodismo visual sobre verificación en colaboración con Salud con Lupa y con el apoyo de Facebook, el International Centre For Journalists, el European Journalism Centre y el Program on Independent Journalism.

En cualquier caso, para periodistas provenientes de medios tradicionales, participar en su creación supone una nueva experiencia de aprendizaje. Así, para la plantilla de EFE Verifica, proveniente de la agencia matriz -en cuyos vídeos no suelen aparecer los redactores-, ha sido la primera en grabar vídeos ante la cámara, como comentaba su responsable, Desireé García. Estos vídeos se caracterizan por un lenguaje más desenfadado y menor rigidez que ante un medio convencional. Desde otros verificadores, como afirma Irene Ignacio de La República, apuntan la importancia de competencias como la narrativa visual o la visualización de datos para un periodista vinculado a verificación, independientemente de que se encargue o no del arte final.

\subsection{Casos significativos de innovación estratégica en adaptación de contenidos}

Además de disponer de personal con competencias para el desarrollo de contenidos innovadores para redes y la gestión de éstas o tener, en su caso, recursos para externalizar estas tareas, los responsables entrevistados coinciden en la importancia de una cultura organizacional que fomente esta innovación conforme a la visión de cada proyecto. Así, Joaquín Ortega, responsable de contenido de Newtral, se refería a que "trasladar todo tipo de información a diversos formatos" forma parte del ADN de la empresa, que emplea además las propias redes sociales para dar a conocer, a través de vídeos y otros recursos multimedia de carácter corporativo, su estrategia de contenidos en redes.

En YouTube está desde abril de 2018, y a inicios de marzo de 2021 supera el millón de visualizaciones según datos de la propia red. Los contenidos aquí son variados, como puede verse en listas, algunas incluso sobre retransmisiones en Twitch. Sobre bulos y verificación destacan la lista de "what the fake" a la que nos referimos, con ejemplos narrados de desinformación sobre la pandemia, y el proyecto "Covidpedia", vídeos elaborados a base de animaciones vectoriales y con voz en off que comparten, en tono divulgativo, información de servicio sobre la pandemia.
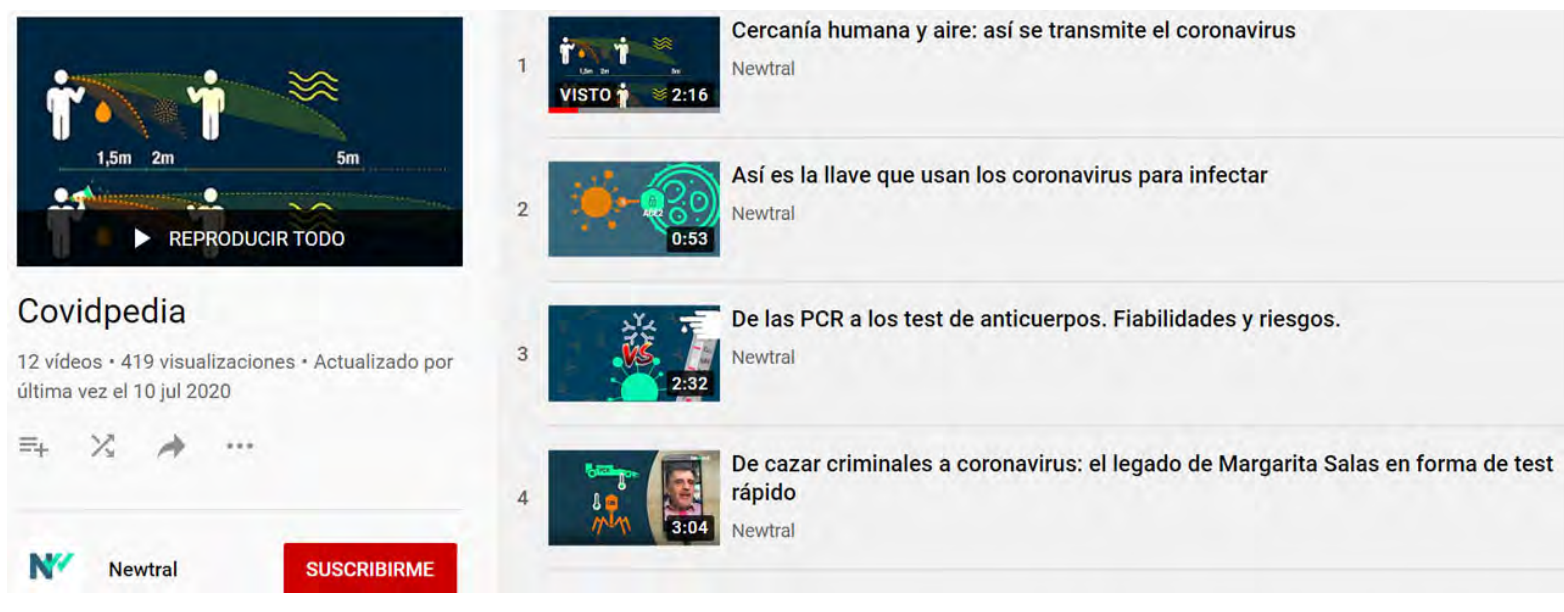

Figura 17: Lista de vídeos de “Covidpedia” en YouTube de Newtral

Fuente: https://bit.ly/3sw4fWj 
Su perfil de Instagram está muy cuidado visualmente, con diseños muy adecuados a la imagen de marca. Tiene además de visualizaciones de datos, infografías y posters tipográficos, numerosos vídeos. Usan mucho IGTV, y en las historias destacadas, como en la propia web, hay una "zona de verificación” dedicada también a información de servicio y bulos desarmados.
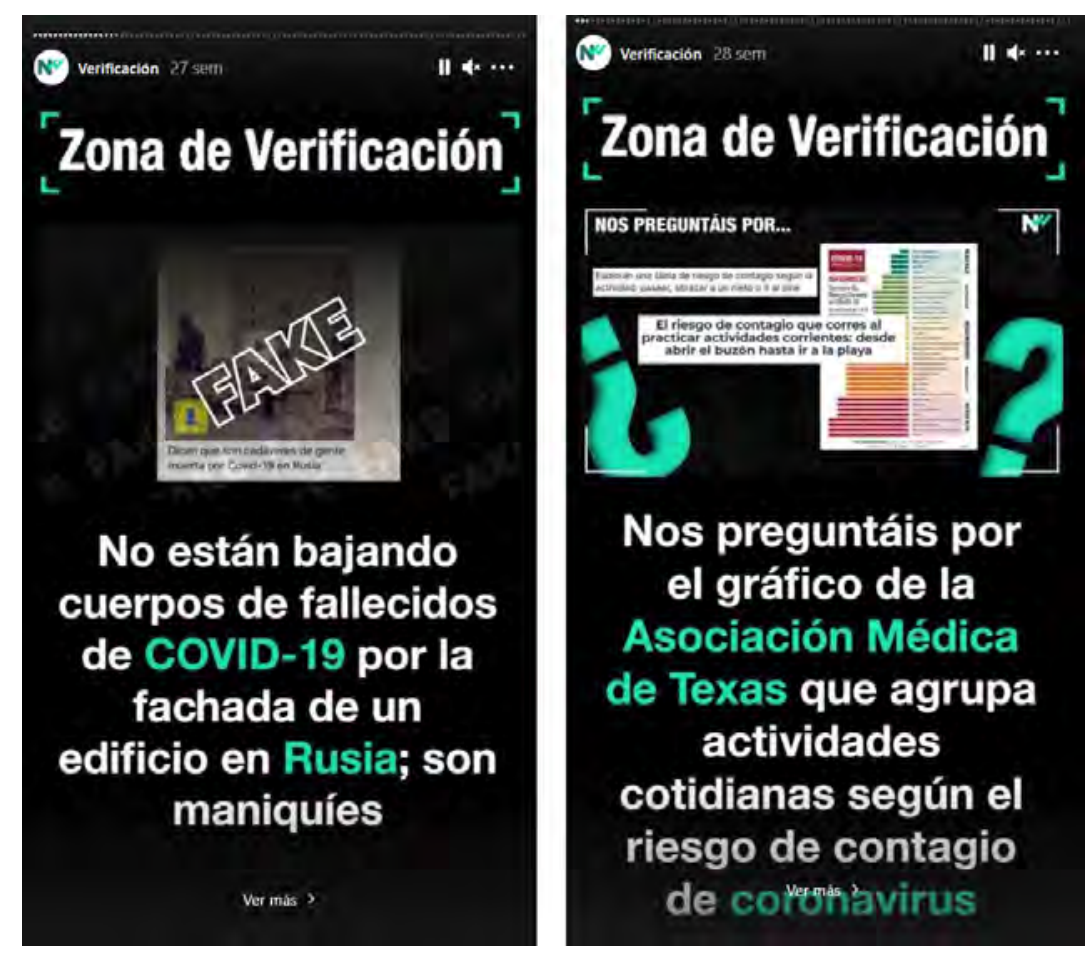

Figura 18: Historias destacadas de verificación en Instagram de Newtral. Fuente: https://bit.ly/2QBd5nl

En Facebook comparten imágenes resultado de sus verificaciones o de proyectos como "el riesgómetro" -herramienta que mide el riesgo de contagio por Covid-19 en distintas actividades ciudadanas con ayuda de expertos en epidemiología y salud pública- y vuelcan como vídeos los contenidos multimedia de otras redes, entre ellos, los mencionados directos de Twitch, los lives de Instagram o los podcasts que, no siempre sobre verificación, también realizan. Su epicentro periodístico está en Twitter, donde usan microvídeos y gráficas animadas para sus posts y hashtags como \#factcheck o \#verificamosparati (este para atender demandas de audiencias) para temas de verificación.
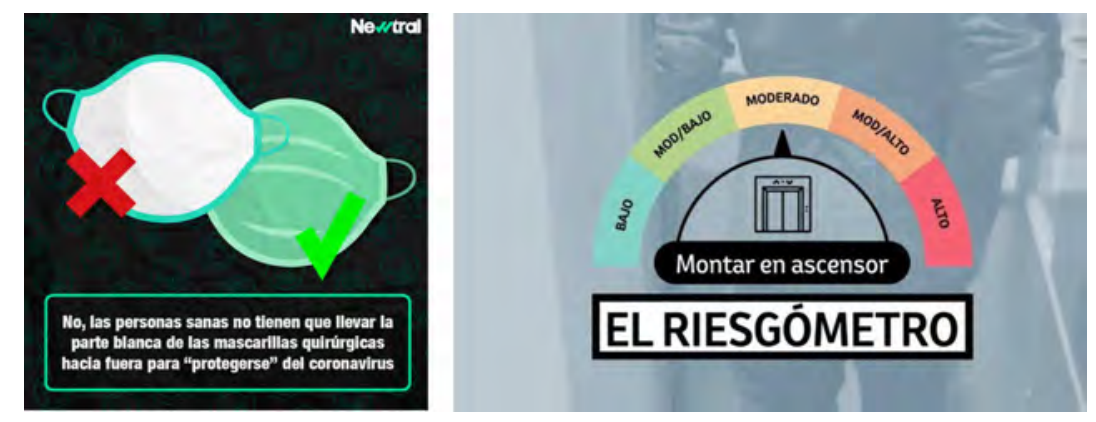

Figura 19: Diseños elaborados, respectivamente, para compartir resultados de verificación y de "El riesgómetro" y compartidas por Newtral como posts en su Facebook.

Fuente: https://www.facebook.com/NewtralMedia

Otro caso significativo en España es Verificat, un proyecto joven y muy orientado a los principios de cultura digital. Surgida en 2019 como primera plataforma independiente de verificación de Cataluña, sus contenidos en redes, como apuntaba Alba Tobella al ser entrevistada, son fruto del trabajo en equipo. Cuentan con periodistas de datos para investigación, uno de los fact checkers es muy activo en visualización de datos y la persona que lleva redes sociales también tiene competencias en diseño 
gráfico. En medio, los coordinadores son quienes deciden qué verificaciones se pueden contar visualmente. Con más de medio centenar de visualizaciones en Flourish, han hecho una fuerte apuesta por crear historias visuales y visualizaciones sobre verificaciones en redes como Instagram, y están trabajando en monográficos especiales.

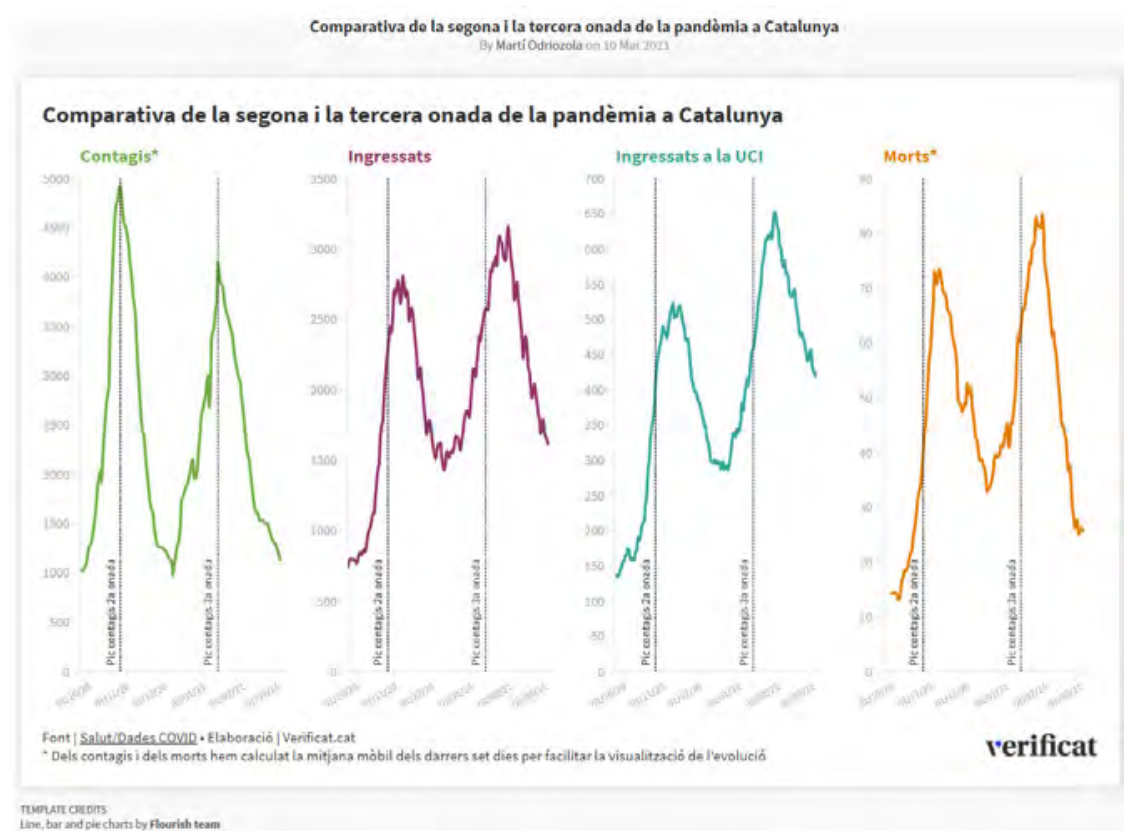

Figura 20: Detalle de una de las visualizaciones de datos interactivas que Verificat suele incluir en sus textos sobre verificaciones y compartir en sus redes, elaborada con Flourish.

Fuente: https://bit.ly/3u0zTeB

A finales de 2020 realizaron una campaña de crowdfunding vía Goteo.org, para cuya difusión se apoyaron sobre todo en Twitter. En palabras de Tobella, entre sus objetivos estaba aumentar su comunidad de lectores, ya que sus seguidores en redes responden a un perfil más joven que el de éstos.

De forma similar, Clara Jiménez, cofundadora y codirectora de Maldita, medio decano en España caracterizado por su tono innovador, cercano e informal, y en beta permanente, apuntaba que "contra todo pronóstico", sus lectores están por encima de los cuarenta y cinco, principalmente, y los cincuenta y cinco años: "No tenemos un gran público joven. Creo que ese es nuestro reto y estamos trabajando en ello a través de TikTok, intentando hacer pildoritas de algunas cosas que atraigan más al público joven, intentando estar más presente en sus redes.”

En este canal, abierto a mediados de 2020 bajo la marca de Maldito Bulo, realizan vídeos de un minuto centrados, entre otros temas de ciencia, en consejos prácticos para prevenir la Covid-19 o en desmentir bulos sobre la pandemia, llegando incluso a apoyarse, para todo ello, en "challenges” (ver imágenes inferiores). Si trabajar de forma directa en redes, creando formatos visuales que los usuarios pudieran enviar enviar por Whatsapp o Telegram o subir a sus perfiles en Facebook y Twitter, fue una de las innovaciones del proyecto en sus arranques (Bernal y Clares, 2019), con estas prácticas vuelven a ser “early adopter” de nuevos canales.

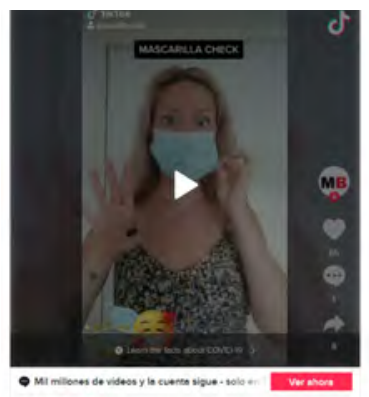

omeldatobulo 0

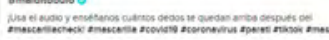

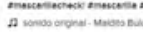

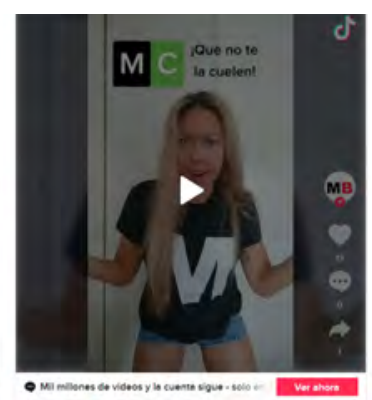

Omi maloner as

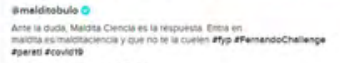

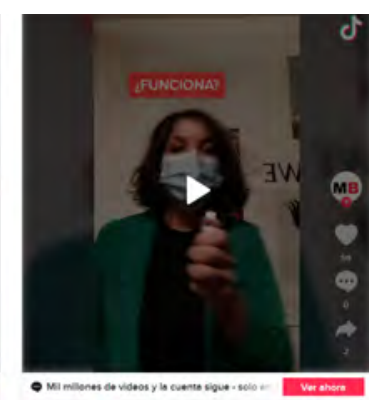

amederebuvio 0

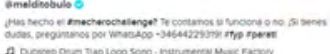


Figura 21: Ejemplos de vídeos vinculados al uso de las mascarillas durante la Covid-19, uno de los temas “estrella” en la fase inicial de la pandemia.

Fuente: TikTok de Maldita, vía https://maldita.es/malditateexplica/20210118/lucha-bulos-desinformacion-tiktok/

El argentino Chequeado, pionero en América Latina, también viene apostando desde sus orígenes por poner "foco en las redes, en lo crowd, como innovación y diferenciación”, en palabras de su fundadora y directora ejecutiva y periodística, Laura Zommer. Desde 2015 cuenta en su estructura con un programa de innovación desde donde se coordinan proyectos de contenidos online a los que da amplia visibilidad en sus redes sociales, como el "Museo de la desinformación" -sitio interactivo lanzado en 2020 con motivo del $10^{\circ}$ aniversario de Chequeado- o "Yo lo chequeo" -herramienta de co-creación en desarrollo a través de la que cualquiera puede verificar contenidos-.

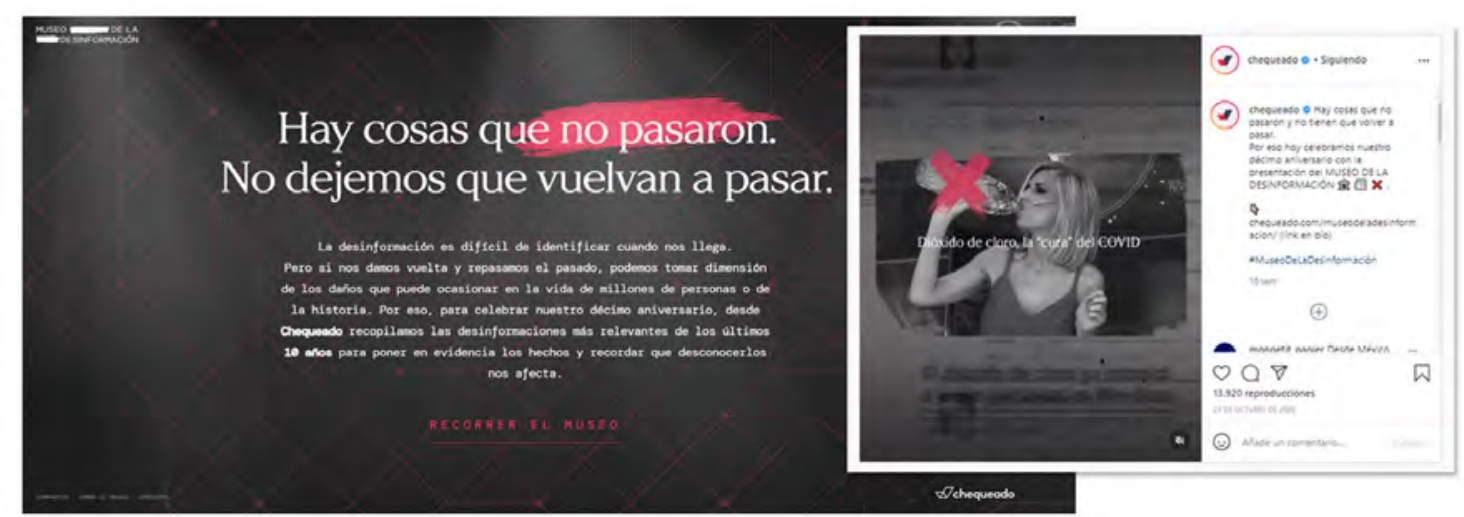

Figura 22: Microsite del Museo de la desinformación y ejemplo de post de promoción en Instagram de Chequeado.

Fuentes: chequeado.com/museodeladesinformacion y https://www.instagram.com/chequeado

Al margen de su gran comunidad en Facebook y, sobre todo, Twitter, en los últimos tiempos han prestado mayor atención a Instagram, según apunta Zommer, por considerarlo un espacio "más constructivo, sin trolls ni haters”, y con enorme potencial, como YouTube, para elaborar contenidos más educativos. Sin presencia aún en TikTok, afirman que su estrategia siempre se ha basado en ir despacio y buscar un "crecimiento sostenido" en el tiempo.

Otro verificador consolidado en el ámbito latinoamericano, Salud con Lupa, viene guiándose por una estrategia consistente en aliarse con científicos para producir contenidos que luego adapta a distintos formatos online primando siempre su utilidad y comprensión para las audiencias según su directora y co-fundadora, Fabiola Torres.

Entre sus proyectos de innovación editorial recientes, "Científicamente comprobado", especial lanzado en marzo de 2021 en colaboración con la Fundación Epistemonikos, responde a este espíritu. En él analizan los tratamientos más usados contra la Covid-19 y los clasifican de acuerdo con su eficacia, permitiendo que los usuarios hagan búsquedas filtradas o amplíen datos sobre cada uno. Contenidos como éste, junto a resultados de investigación en torno a la pandemia (\#vacunagate, por ejemplo, en Twitter) y otros de divulgación y alfabetización de carácter visual ya comentados, ocupan sus canales en redes sociales.

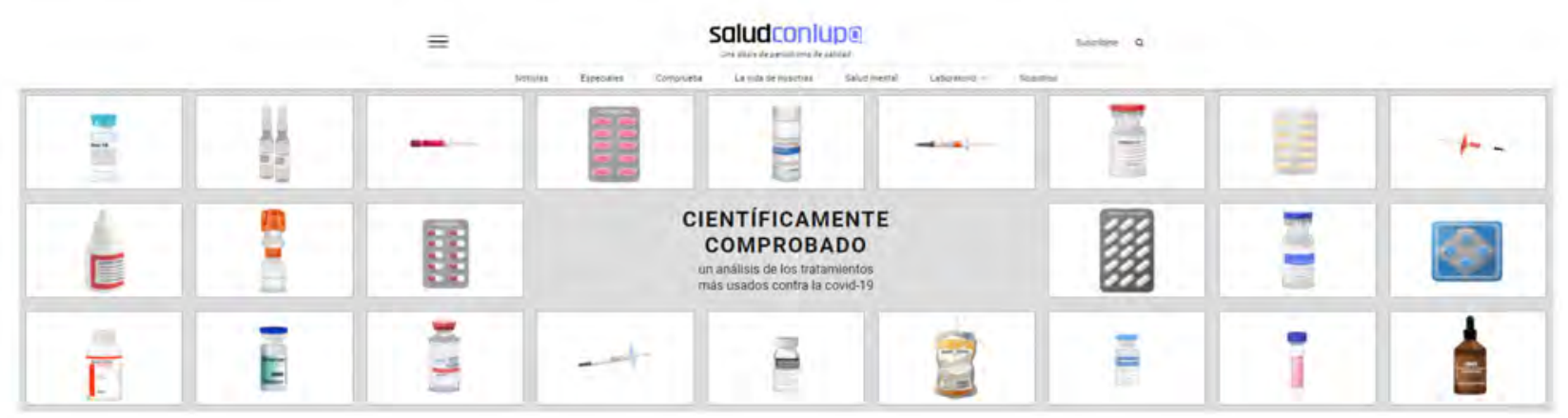




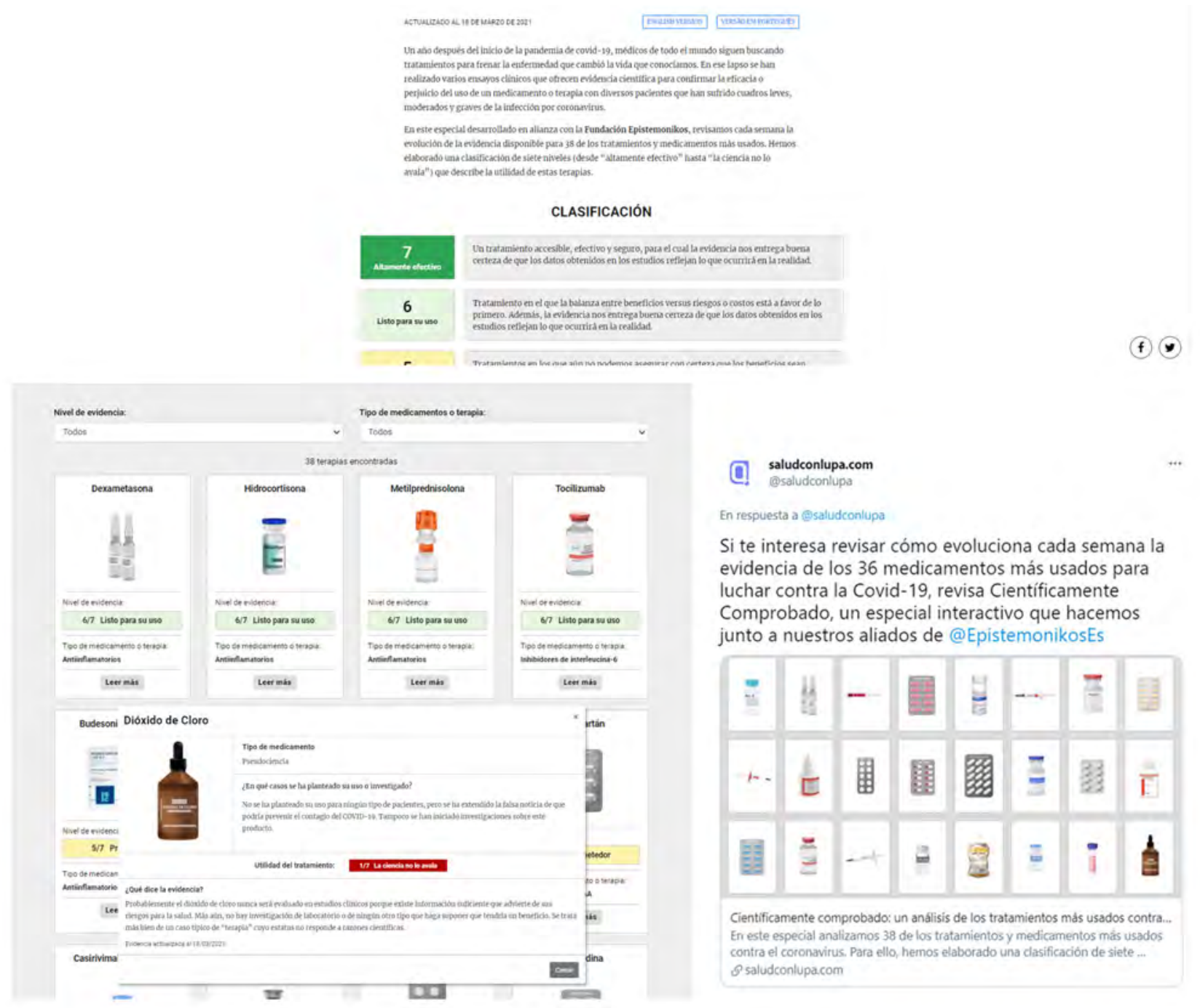

Figura 23: Extractos del microsite de "Científicamente comprobado" y tweet publicado el 12 de febrero de 2021 anunciando estos contenidos.

Fuentes: $\underline{\text { https://bit.ly/3w9n4AA y https://bit.ly/3lXSrtr }}$

\subsection{Distintas fases, misma conciencia}

La producción propia de contenidos para redes sociales se sitúa, según confirman sus propios promotores, entre la estrategia (con planes editoriales y acciones para la escucha activa de audiencias online, seguimiento y evaluación de los resultados) y la experimentación.

Muchos verificadores se enfocan hoy en la calidad de la información más que en adaptar sus formatos. Otros están en la fase generación de comunidad, como el Verificador de La República según su coordinadora de contenidos, Irene Ignacio, y dejan para siguientes fases la innovación en formatos.

Entre casos significativos de adaptación orquestada de contenidos de verificación para distintos públicos y como parte de una estrategia (planes editoriales y alfabetización mediática), destaca, además de los reseñados, El Sabueso de México. Como contaba su editora general, Tania Montalvo, su producto principal son vídeos de verificación dirigidos a audiencias jóvenes y cuyos temas se deciden "en función de los comentarios de la gente en torno a una verificación". Para un público distinto, "un poco mayor" elaboran infografías "ligeras" y en ocasiones "divertidas" para facilitarles la información. Con la pandemia, además, consolidaron sus "explainers", textos largos donde explican de principio a fin, sin decir si algo es verdadero o falso, los detalles de un tema para "prevenir la desinformación”. Todos estos contenidos, además de en redes sociales, se encuentran clasificados desde su web. 
Otro verificador con una estrategia muy definida y adaptada a las peculiaridades de su territorio es, como se adelantó, Ojo Biónico de Ojo Público. Como parte de su función social viene produciendo contenidos traducidos a lenguas indígenas y pensados para ser distribuidos a públicos con conectividad limitada, no sólo en redes sino vía dispositivos móviles o radio, gracias a colaboraciones con actores locales. Su director de noticias, David Hidalgo, se refería a todo ello como "metodología de guerrillas" que, a través de la combinación de arte, música y otras disciplinas, pretende alfabetizar contra la desinformación ante la Covid-19 en zonas rurales.

Algunos responsables insisten en la importancia de adaptar los contenidos según distintos niveles de compromiso de la audiencia y de incluir en sus planes indicadores para el seguimiento de resultados online. Como apuntaba Gabriela Brenes, directora ejecutiva de La Voz de Guanacaste, para incorporar un producto periodístico, "lo primero y más retador" es "no guiarse por la intuición y medir el impacto para que la experimentación sea intencional”.

\section{Conclusiones}

Ninguno de los verificadores hispanos de la \#CoronavirusFactCheck Alliance pone en duda hoy la importancia que las redes sociales y la innovación editorial en éstas tienen para su actividad. Como apuntaba Tania Montalvo de El Sabueso de Animal Político, "la desinformación se tiene que atacar en formatos distintos en función de cómo se esté moviendo". En un contexto en el que, en palabras de Irene Ignacio, del Verificador de La República, "algo de lo que se acusa a los verificadores es de hacer periodismo sólo para periodistas", difundir su trabajo empleando los mismos canales y plataformas desde los que sigue fluyendo la desinformación (Bustos y Ruiz del Olmo, 2020) y con formatos más viralizables que un texto o post (Bernal y Gavilán, 2019), les está permitiendo llegar a más usuarios y superar este mito.

Con independencia de que se realicen de forma estratégica o táctica y de las fórmulas que adopten, las prácticas de difusión y, en su caso, generación de contenidos en red de los verificadores obedecen, atendiendo a sus responsables, a un doble objetivo. Por un lado, pretenden contribuir a su misión y actuar en coherencia a sus valores y principios, de los cuales la replicabilidad, transparencia, alfabetización y función social son parte esencial. Por otro lado, estas prácticas persiguen aproximarse a las audiencias, atender a sus demandas para fidelizar, al tiempo que captan nuevos usuarios en determinados canales en red, y con todo ello, extienden su labor como verificadores y son más eficaces en la lucha contra la desinformación. Adaptarse a las necesidades de los diversos públicos se vuelve esencial, así como hacerlo bajo el principio de sostenibilidad. Como afirmaba Gabriela Brenes de La Voz de Guanacaste, "no se compite tanto por volumen sino por engagement".

Convertidos, más que en simples medios o plataformas de verificación, en productores y distribuidores de contenidos multimedia en red con los que informar, formar e, incluso, movilizar en la lucha contra la infodemia a la ciudadanía, existe una autopercepción positiva generalizada acerca de los resultados obtenidos por quienes han desarrollado prácticas en este sentido.

Las prácticas más innovadoras, de carácter fundamentalmente audiovisual, son, aunque incipientes, muy significativas, y denotan las posibilidades de los fact checkers, por su naturaleza y singularidad, para ir más allá que los medios convencionales en cuanto a experimentación. Lo hacen con formatos y narrativas online que mezclan información y entretenimiento (con un componente también educativo), beben de principios y fórmulas propias de la cultura digital, como el visual thinking y la visualización, la remezcla y el meme y, en cierta forma, la gamificación. Y se distribuyen en canales donde abundan los boomers, la Generación X o los millennials, aprovechando también el consumo de éstos vía móvil (Pellicer, 2019).

Lo cierto es que éstas se dan sobre todo en proyectos que cuentan ya con cierta trayectoria o en los que surgen bajo la filosofía de startups, con la innovación como parte de su misión y valores y donde se da prioridad a la adaptación de contenidos. Salvo excepciones, en micromedios con recursos limitados o dependientes de ayudas o grants, gran parte de los esfuerzos siguen centrados en redes tradicionales, como Twitter o Facebook, y su presencia en ellas obedece en gran parte a la necesidad de disponer de canales para comunicarse con las audiencias y que estas remitan sus demandas de verificación. 
Factores como la falta de planificación, la escasez de tiempo o la disponibilidad/cualificación del personal para hacer escucha activa de redes y producir nuevos contenidos adaptados a demandas, son dificultades frecuentes en muchos de los verificadores hispanos analizados. Se enfrentan a un reto que es “tecnológico, pero sobre todo narrativo”, en palabras de Gabriela Brenes, de La Voz de Guanacaste, quien aboga por una estrategia futura de "marca modular", esto es, "empaquetar lo verificado en distintos formatos y publicar contenido de mayor impacto" pensando en distintos públicos. Algunas de las secciones, como Verificador de La República tienen entre sus planes, atendiendo a su responsable, Irene Ignacio, aprovechar los equipos de los medios matriz, con expertos en visualización de datos, para desarrollar proyectos cruzados.

En cualquier caso, formar parte de la alianza \#CoronavirusFactCheck y de la propia IFCN les abre a todos nuevas oportunidades, que de hecho ya están viendo sus frutos. Entre ellas, poder disponer de tecnologías y herramientas para anticiparse y hacer escucha activa de desinformaciones en redes sociales. Pero, sobre todo, sumar fuerzas para impulsar proyectos colaborativos de innovación editorial o desarrollar iniciativas propias con el soporte de organismos y entidades a los que, gracias al prestigio y credibilidad que otorga ser parte de esta red mundial, tienen más fácil acceso.

\section{Referencias}

Aguado-Guadalupe, G. y Bernaola-Serrano, I. (2020). Verificación en la infodemia de la Covid-19. El caso Newtral. Revista Latina de Comunicación Social, 78, 289-308.

https://doi.org/10.4185/rlcs-2020-1478.

Amorós, M. (2018). Fake News. La verdad de las noticias falsas. Plataforma Editorial.

Amazeen, M. A. (2017). Journalistic interventions: The structural factors affecting the global emergence of fact-checking. Journalism, 21(1), 95-111. https://doi.org/10.1177/1464884917730217.

Ballesteros Herencia, C. A. (2020). La propagación digital del coronavirus: Midiendo el engagement del entretenimiento en la red social emergente TikTok. Revista española de comunicación en salud, 171. https://doi.org/10.20318/recs.2020.5459.

Bernal-Triviño, A. y Clares-Gavilán, J. (2019). Uso del móvil y las redes sociales como canales de verificación de fake news. El caso de Maldita.es. El Profesional de la Información, 28(3).

https://doi.org/10.3145/epi.2019.may.12.

Blanco Alfonso, I., García Galera, C. y Tejedor Calvo, S. (2019). El impacto de las fake news en la investigación en Ciencias Sociales. Revisión bibliográfica sistematizada. Historia y Comunicación Social, 24(2), 449-469. https://doi.org/10.5209/hics.66290.

Bustos, J. y Ruiz del Olmo, F- J. (2020). Fuentes verificadas ante las Fakes News. El caso de Facebook, Google y Microsoft frente a la desinformación durante el Covid-19. Revista De Estilos De Aprendizaje, 13(26), 7-18. ISSN: 1988-8996/ ISSN:2332-8533.

Callejo, J. (1998). Los límites de la formalización de las prácticas cualitativas de investigación social. Sociológica. Revista de pensamiento social, 3, 93-119. http://hdl.handle.net/2183/2707.

Cinelli, M., Quattrociocchi, W., Galeazzi, A., Valensise, C. M., Brugnoli, E., Schmidt, A. L., Zola, P., Zollo, F. y Scala, A. (2020). The COVID-19 social media infodemic. Scientific Reports, 10(1). https://doi.org/10.1038/s41598-020-73510-5.

Conde-Vázquez, E., Fontenla-Pedreira, J. y Pereira-López, M. (2020). Fake News y Fact-checking en la cobertura mediática durante la crisis del Covid-19 en España: el caso de Newtral y Maldito Bulo. Revista Ibérica de Sistemas e Tecnologias de Informação, 35, 559-571.

Dafonte-Gómez, A., Martínez-Rolán, X. y Corbacho-Valencia, J.M. (2019). Mapa de los Fact-Checkers Iberoamericanos: presencia en redes y vías de difusión de contenidos. En Versuti, A., Escudero, C., Mier, C., Assis, C., Santinello, J., de Lucena Ito, L., \& Longui, R. (Eds.) Meios e transformacão 
social (pp. 198-217). Ria Editorial.

García Vivero, G. y López, X. (2021). La verificación de datos en Europa. Análisis de 5 iniciativas europeas: Maldita.es, Newtral, Pagella Politica, Les Décodeurs y BBC Reality Check. adComunica, 235-264. https://doi.org/10.6035/2174-0992.2021.21.12.

García-Marín, D. (2020). Infodemia global. Desórdenes informativos, narrativas fake y fact-checking en la crisis de la Covid-19. El profesional de la información, 29(4), e290411.

https://doi.org/10.3145/epi.2020.jul.11.

González, S. (2020). La batalla informativa contra las fake news. El caso de Newtral en Instagram. En De Vicente, Aída M. y Sierra, J. S. (coords.). Aproximación periodística y educomunicativa al fenómeno de las redes sociales (pp. 1003-1017). McGraw-Hill Interamericana de España.

Guallar, J., Codina, L., Freixa, P. y Pérez-Montoro, M. (2020). Desinformación, bulos, curación y verificación. Revisión de estudios en Iberoamérica 2017-2020. Telos: Revista de Estudios Interdisciplinarios en Ciencias Sociales, 22(3), 595-613. https://doi.org/10.36390/telos223.09.

Kovach, B. y Rosenstiel, T. (2003). Los elementos del periodismo. Ediciones El País.

Rodríguez Rodríguez, J. M. y López Pan, F. (2020). El Fact Checking en España. Plataformas, prácticas y rasgos distintivos. Estudios sobre el Mensaje Periodístico, 26(3), 1045-1065.

https://doi.org/10.5209/esmp.65246.

Lopez-Borrull, A., Vives-Gràcia, J. y Badell, J. I. (2018). Fake news, ¿amenaza u oportunidad para los profesionales de la información y la documentación? El Profesional de la Información, 27(6), 13461356. https://doi.org/10.3145/epi.2018.nov.17.

Magallón Rosa, R. (2019). Verificado México 2018. Desinformación y fact-checking en campaña electoral. Revista de Comunicación, 18(1), 234-258. https://doi.org/10.26441/rc18.1-2019-a12.

Martisi, B. C. (2021, 15 julio). Desinformación y 'fake news'durante la COVID-19: cómo cortar la red de contagio. Compromiso Empresarial.

https://www.compromisoempresarial.com/coronavirus/2020/04/desinformacion-fake-news-tiempos-covid19-como-evitarla/.

Morales, E. (2018). Desinformación en la Sociedad de la Información y el Conocimiento. En Morales, E. (ed). La posverdad y las noticias falsas: el uso ético de la información. UNAM.

Masip, P., Aran-Ramspott, S., Ruiz-Caballero, C., Suau, J., Almenar, E. y Puertas-Graell, D. (2020). Consumo informativo y cobertura mediática durante el confinamiento por el Covid-19: sobreinformación, sesgo ideológico y sensacionalismo. El Profesional de la Información, 29(3), 1-12.

https://doi.org/10.3145/epi.2020.may.12.

Noain Sánchez, A. (2019). Periodismo de confirmación vs. Desinformación: verificado18 y las elecciones mexicanas de 2019. Ámbitos. Revista Internacional de Comunicación, 43, 95-114.

https://doi.org/10.12795/ambitos.2019.i43.05.

Palau-Sampio, D. (2018). Fact-checking y vigilancia del poder: La verificación del discurso público en los nuevos medios de América Latina. Communication \& Society, 31(3), 347-365.

https://doi.org/10.15581/003.31.3.347-363.

Palomo, B. y Sedano, J. (2018). WhatsApp como herramienta de verificación de fake news. El caso de B de Bulo. Revista Latina de Comunicación Social, 73, 1384-1397.

https://doi.org/10.4185/rlcs-2018-1312.

Pellicer, M. (2020, 21 septiembre). TikTok: Cómo puede ayudar a los medios de comunicación. MiquelPellicer.com. 
https:/miquelpellicer.com/2019/07/tiktok-como-puede-ayudar-a-los-medios-de-comunicacion/.

Pérez-Dasilva, J. A., Meso-Ayerdi, K. y Mendiguren-Galdospín, T. (2020). Fake news y coronavirus: detección de los principales actores y tendencias a través del análisis de las conversaciones en Twitter. El Profesional de la Información, 29(3), 1-22. https://doi.org/10.3145/epi.2020.may.08.

Ramon-Vegas, X., Mauri-Ríos, M. y Rodríguez-Martínez, R. (2020). Redes sociales y plataformas de fact-checking contra la desinformación sobre la COVID-19. Hipertext.net, 21, 79-92. https://doi.org/10.31009/hipertext.net.2020.i21.07.

Rodríguez Pérez, C. (2020). Una reflexión sobre la epistemología del fact-checking journalism: retos y dilemas. Revista de Comunicación, 19(1), 243-258. https://doi.org/10.26441/rc19.1-2020-a14.

Salaverría, R., Buslón, N., López-Pan, F., León, B., López-Goñi, I. y Erviti, M. C. (2020). Desinformación en tiempos de pandemia: tipología de los bulos sobre la Covid-19. El Profesional de la Información, 29(3). https://doi.org/10.3145/epi.2020.may.15.

Sánchez, H.M. (2020, 11 de mayo). Anatomía de un bulo. Cibersur (entrevista por José Muros) http://www.cibersur.com/cibersur/impe/empresa/020967/anatomia/bulo.

Sánchez-Duarte, J. M. y Magallón Rosa, R. (2020). Infodemia y COVID-19. Evolución y viralización de informaciones falsas en España. Revista española de comunicación en salud, 31, 31-41.

https://doi.org/10.20318/recs.2020.5417.

Spivak, C. (2011). The fact-checking explosion: in a bitter political landscape marked by rampant allegations of questionable credibility, more and more news outlets are launching truth-squad operations. American Journalism Review, 32(4).

https://link.gale.com/apps/doc/A245543278/AONE?u=anon 3b69b4de\&sid=googleScholar\&xi$\underline{\mathrm{d}=1460 \mathrm{afbc}}$.

Ufarte-Ruiz, M. J., Anzera, G. y Murcia-Verdú, F. J. (2020). Plataformas independientes de fact-checking en España e Italia. Características, organización y método. Revista Mediterránea de Comunicación, 11(2), 23-39. https://doi.org/10.14198/medcom2020.11.2.3.

Vázquez-Herrero, J., Vizoso, N. y López-García, X. (2019). Innovación tecnológica y comunicativa para combatir la desinformación: 135 experiencias para un cambio de rumbo. El Profesional de la Información, 28(3), 1-12. https://doi.org/10.3145/epi.2019.may.01.

Villa Gracia, A. D. y Cerdán Martínez, V. (2020). Bulos durante la pandemia del Covid-19 en España: un estudio a través de Google Trends. Revista Latina de Comunicación Social, 78, 169-182.

https://doi.org/10.4185/rlcs-2020-1473.

Vizoso, N. y Vázquez-Herrero, J. (2019). Fact-checking platforms in Spanish. Features, organisation and method. Communication \& Society, 32(1), 127-142. https://doi.org/10.15581/003.32.1.127-144.

\section{AUTOR/ES:}

\section{María Sánchez González}

Universidad de Málaga

Profesora asociada doctora en Periodismo de la Universidad de Málaga y técnico en Innovación de la Universidad Internacional de Andalucía. Acreditada como profesora titular por ANECA (diciembre de 2020). Actualmente es investigadora del proyecto de I+D+i "Impacto de la desinformación en el periodismo: contenidos, rutinas profesionales y audiencias (DESINFOPER)”, PID2019-108956RB-I00 (Ministerio de Ciencia e Innovación de España); y de "MEDIO: Media \& Data Innovation" (SEJ 612) de la Junta de Andalucía. También coordina y participa en varios proyectos/redes de innovación educativa. Líneas de investigación: contenidos y cultura digital; social media; audiencias activas y participación ciudadana; innovación; emprendimiento digital; y verificación periodística. Asimismo, 
cuenta con diversas publicaciones abiertas sobre formación de profesorado, aprendizaje en red y competencias digitales.

m.sanchezgonzalez@uma.es

Î́ndice H: 14

Scopus ID: 55064941400

Orcid ID: https://orcid.org/0000-0003-3053-0646

Google Scholar: https://scholar.google.es/citations?user=mZj8Sm8AAAAJ\&hl=es

ResearchGate: https://www.researchgate.net/profile/Maria-Sanchez-Gonzalez-3

Academia.edu: https://unia.academia.edu/mariaS\%C3\%A1nchez

\section{Hada M. Sánchez Gonzales}

Universidad de Sevilla

Profesora Titular en Periodismo de la Universidad de Sevilla. Vicedecana de Comunicación, Relaciones Institucionales y Emprendimiento de la Facultad de Comunicación. Además, dirige el Laboratorio de Proyectos en Comunicación (LabProCom), el Grupo de Investigación Análisis y Técnica de la Información (GIATI) y la revista científica "Textual \&Visual Media". Especializada en medios digitales; social media, rutinas y perfiles periodísticos; innovación periodística, emprendimiento digital y audiencias activas. Es autora de un centenar de artículos y libros sobre estos temas. Participa en proyectos competitivos a nivel internacional, nacional y regional y sus resultados han tenido un impacto transfronterizo. Cuenta con sexenios de transferencia e investigación y forma parte del cuerpo de evaluadores de la Agencia Nacional de Evaluación y Prospectiva (ANEP). Es investigadora del proyecto de I+D+i "Impacto de la desinformación en el periodismo: contenidos, rutinas profesionales y audiencias (DESINFOPER)”, PID2019-108956RB-I00 (Ministerio de Ciencia e Innovación de España).

misago@us.es

\section{Índice H: 8}

Scopus ID: 55772459800

Orcid ID: https://orcid.org/0000-0001-5078-2184

Google Scholar: https://scholar.google.es/citations?user=iNbWIvIAAAAJ\&hl=es

ResearchGate: https://www.researchgate.net/profile/Hada-Sanchez-Gonzales

Academia.edu: https://us.academia.edu/HS\%C3\%A1nchez

\section{Javier Martos}

Universidad de Sevilla

Periodista e investigador. Doctorando interuniversitario en Comunicación en la Universidad de Sevilla. Miembro del Laboratorio de Proyectos de Comunicación (LabProCom). Máster en Comunicación Institucional y Política por la Universidad de Sevilla. Ha trabajado en medios de comunicación (TV, radio y prensa) y gabinetes de comunicación. En los últimos años ha participado como autor y ponente en varios congresos nacionales e internacionales de comunicación (IAMCR, SEP, Congreso Internacional de Comunicación y Pensamiento...), sobre periodismo, audiencia y comunicación digital. Premio Open Innovation Sevilla en 2019. También cuenta con varias publicaciones acerca de las plataformas de mensajería y su influencia en los medios de comunicación y los partidos políticos.

javiermm94@gmail.com

Orcid ID: https://orcid.org/0000-0002-1659-3723

\section{ANEXOS:}

Anexo 1. Tabla 2. Presencia en redes sociales de verificadores

\begin{tabular}{|l|l|l|l|l|}
\hline $\begin{array}{l}\text { Tipo de } \\
\text { verificador }\end{array}$ & Nombre del verificador & Tipo de canales & Canales propios & Canales del medio \\
\hline Medio & Agencia Lupa & Propios & $\begin{array}{l}\text { Twitter, Facebook, Instagram, } \\
\text { YouTube, Flipboard, Otras }\end{array}$ & \\
\hline Medio & Aos Fatos & Propios & $\begin{array}{l}\text { Twitter, Facebook, Instagram, } \\
\text { YouTube }\end{array}$ & \\
\hline
\end{tabular}


RLCS, Revista Latina de Comunicación Social, 80, 135-161

[Investigación] https://www.doi.org/10.4185/RLCS-2022-1535| ISSN 1138-5820 | Año 2022

\begin{tabular}{|c|c|c|c|c|}
\hline Medio & Bolivia Verifica & Propios & $\begin{array}{l}\text { Twitter, Facebook, Instagram, } \\
\text { YouTube }\end{array}$ & \\
\hline Medio & Chequeado & Propios & $\begin{array}{l}\text { Twitter, Facebook, Instagram, } \\
\text { YouTube }\end{array}$ & \\
\hline Medio & Colombia Check & Propios & $\begin{array}{l}\text { Twitter, Facebook, Instagram, } \\
\text { YouTube, Otras }\end{array}$ & \\
\hline Medio & Cotejo.info & Propios & Twitter, Facebook, Instagram & \\
\hline Medio & Ecuador Chequea & Propios & $\begin{array}{l}\text { Twitter, Facebook, Instagram, } \\
\text { YouTube, Otras }\end{array}$ & \\
\hline Medio & Newtral & Propios & $\begin{array}{l}\text { Twitter, Facebook, Instagram, } \\
\text { YouTube }\end{array}$ & \\
\hline Medio & Polígrafo & Propios & Twitter, Facebook, Instagram & \\
\hline Medio & Spondeo Media & Propios & $\begin{array}{l}\text { Twitter, Facebook, Instagram, } \\
\text { YouTube }\end{array}$ & \\
\hline Medio & $\begin{array}{l}\text { Salud con Lupa (Com- } \\
\text { prueba) }\end{array}$ & Propios & $\begin{array}{l}\text { Twitter, Facebook, Instagram, } \\
\text { YouTube }\end{array}$ & \\
\hline Medio & Verificado & Propios & Twitter, Facebook & \\
\hline Medio & Verificat & Propios & Twitter, Facebook, Instagram & \\
\hline Sección & Maldita (Maldito Bulo) & Mixtos & Twitter, YouTube, TikTok & $\begin{array}{l}\text { Twitter, Facebook, Insta- } \\
\text { gram, Otras }\end{array}$ \\
\hline Sección & $\begin{array}{l}\text { Animal Político (El } \\
\text { Sabueso) }\end{array}$ & Mixtos & Twitter, Facebook & $\begin{array}{l}\text { Twitter, Facebook, } \\
\text { Instagram, YouTube, } \\
\text { Flipboard, Otras }\end{array}$ \\
\hline Sección & $\begin{array}{l}\text { Verificador de La Re- } \\
\text { pública }\end{array}$ & Mixtos & Twitter, Facebook & $\begin{array}{l}\text { Twitter, Facebook, Insta- } \\
\text { gram }\end{array}$ \\
\hline Sección & AFP Factual & Mixtos & Twitter, Facebook & $\begin{array}{l}\text { Twitter, Facebook, Insta- } \\
\text { gram, YouTube, Otras }\end{array}$ \\
\hline Sección & Agencia Ocote & Del medio & & $\begin{array}{l}\text { Twitter, Facebook, Insta- } \\
\text { gram, YouTube, Otras }\end{array}$ \\
\hline Sección & Convoca & Del medio & & $\begin{array}{l}\text { Twitter, Facebook, You- } \\
\text { Tube }\end{array}$ \\
\hline Sección & EFE Verifica & Del medio & & $\begin{array}{l}\text { Twitter, Facebook, Insta- } \\
\text { gram, YouTube, Otras }\end{array}$ \\
\hline Sección & Efecto Cocuyó & Del medio & & $\begin{array}{l}\text { Twitter, Facebook, Insta- } \\
\text { gram, YouTube }\end{array}$ \\
\hline Sección & El Surtidor & Del medio & & $\begin{array}{l}\text { Twitter, Facebook, Insta- } \\
\text { gram, YouTube, TikTok, } \\
\text { Otras }\end{array}$ \\
\hline Sección & Estadão Verifica & Del medio & & $\begin{array}{l}\text { Twitter, Facebook, Insta- } \\
\text { gram, Otras }\end{array}$ \\
\hline Sección & La Nación & Del medio & & $\begin{array}{l}\text { Twitter, Facebook, Insta- } \\
\text { gram }\end{array}$ \\
\hline Sección & La Voz de Guanacaste & Del medio & & $\begin{array}{l}\text { Twitter, Facebook, Insta- } \\
\text { gram, YouTube }\end{array}$ \\
\hline Sección & La Silla Vacía & Del medio & & $\begin{array}{l}\text { Twitter, Facebook, You- } \\
\text { Tube }\end{array}$ \\
\hline Sección & Observador & Del medio & & $\begin{array}{l}\text { Twitter, Facebook, Insta- } \\
\text { gram, YouTube, TikTok, } \\
\text { Otras }\end{array}$ \\
\hline
\end{tabular}


RLCS, Revista Latina de Comunicación Social, 80, 135-161

[Investigación] https://www.doi.org/10.4185/RLCS-2022-1535| ISSN 1138-5820 | Año 2022

\begin{tabular}{|l|l|l|l|l|}
\hline Sección & $\begin{array}{l}\text { Ojo Público (Ojo bió- } \\
\text { nico) }\end{array}$ & Del medio & & $\begin{array}{l}\text { Twitter, Facebook, Insta- } \\
\text { gram, YouTube }\end{array}$ \\
\hline Sección & Periodismo de barrio & Del medio & $\begin{array}{l}\text { Twitter, Facebook, Instagram, } \\
\text { YouTube, Otras }\end{array}$ & \\
\hline
\end{tabular}

Fuente: elaboración propia con datos de febrero de 2021 